\title{
Divergence in the face of gene flow in two Charadrius plovers along the \\ 2 Chinese coast
}

4 Xuejing Wang ${ }^{1 \S}$, Pinjia Que ${ }^{2 \S}$, Gerald Heckel ${ }^{3,5}$, Junhua Hu ${ }^{4}$, Xuecong Zhang ${ }^{1}$, Chung-Yu Chiang ${ }^{6}$, Qin Huang ${ }^{1}$, Simin Liu' ${ }^{1}$, Jonathan Martinez ${ }^{7}$, Nan Zhang ${ }^{1}$, Emilio

6 Pagani-Núñez ${ }^{1}$, Caroline Dingle ${ }^{8}$, Leung Yu Yan ${ }^{8}$, Tamás Székely ${ }^{1,9}$, Zhengwang Zhang ${ }^{2}$, Yang Liu ${ }^{1 *}$

8

1. State Key Laboratory of Biocontrol, Department of Ecology, School of Life

2. Ministry of Education Key Laboratory for Biodiversity and Ecological

143. Institute of Ecology and Evolution, University of Bern, Baltzerstrasse 6, 3012 Bern, Switzerland

164 4. Chengdu Institute of Biology, Chinese Academy of Sciences, Chengdu 610041, China

18 5. Swiss Institute of Bioinformatics, Genopode, 1015 Lausanne, Switzerland

6. Department of Environmental Science, Tunhai University, Taichun, Taiwan, China

7. 14, bis rue des Temples 45240 La Ferté Saint Aubin, France

8. School of Biological Sciences, The University of Hong Kong, Hong Kong

$$
\text { S.A.R., China }
$$

9. Milner Center for Evolution, Department of Biology and Biochemistry,

University of Bath, Bath BA1 7AY, UK

26 Running title: Incipient speciation in Charadrius plovers

Total words (without reference): 7930

References $\square 133$ 
30 *Correspondence: Yang Liu, School of Life Sciences, Sun Yat-sen University, Guangzhou, China. Email: liuy353@mail.sysu.edu.cn;

$32 \S$ These authors contributed equally to this work.

\section{Abstract}

36 Speciation with gene flow is an alternative to the nascence of new taxa in strict allopatric separation. Indeed, many taxa have parapatric distributions at present. It is often unclear if these are secondary contacts, e.g. caused by past glaciation cycles or the manifestation of speciation with gene flow, which hampers our understanding of how different forces drive diversification. Here we studied genetic, phenotypic and ecological aspects of divergence in a pair of incipient species, the Kentish (Charadrius

42 alexandrinus) and the white-faced Plovers (C. dealbatus), shorebirds with parapatric breeding ranges along the Chinese coast. We assessed divergence based on

44 molecular markers with different modes of inheritance and quantified phenotypic and ecological divergence in aspects of morphometric, dietary and climatic niches. These

46 analyses revealed small to moderate levels of genetic and phenotypic distinctiveness with symmetric gene flow across the contact area at the Chinese coast. The two

48 species diverged approximately half a million years ago in dynamical isolation and secondary contact due to cycling sea level changes between the Eastern and

50 Southern China Sea in the mid-late Pleistocene. We found evidence of character displacement and ecological niche differentiation between the two species, invoking

52 the role of selection in facilitating divergence despite gene flow. These findings imply that the ecology can indeed counter gene flow through divergent selection and thus

54 contribute to incipient speciation in these plovers. Furthermore, our study highlights the importance of using integrative datasets to reveal the evolutionary history and underlying mechanisms of speciation. 
bioRxiv preprint doi: https://doi.org/10.1101/406041; this version posted August 31, 2018. The copyright holder for this preprint (which was not certified by peer review) is the author/funder, who has granted bioRxiv a license to display the preprint in perpetuity. It is made available under aCC-BY-NC-ND 4.0 International license.

KEY WORDS: allopatric speciation, character displacement, gene flow, hybridization, stable isotope analysis, ecological niche 


\section{INTRODUCTION}

60 Understanding how strongly the evolutionary processes, i.e. selection, gene flow and genetic drift shape the divergence of closely related species has been a long-standing

62 interest in evolutionary biology (Coyne \& Orr 2004; Feder et al. 2013; Nosil \& Feder 2012; Wagner et al. 2012; Wolf \& Ellegren 2017). Allopatric speciation is

64 conventionally considered as the prevalent mode of speciation in which physical barriers completely restrict gene flow between two populations, facilitating the initiation

66 of divergence through genetic drift or selection (Bernardi et al. 2008; Carson \& Clague 1995; Mayr 1963). If populations remain isolated for a period long enough after

68 divergence has been established, then this divergence could be maintained even in the presence of gene flow after secondary contact (Le Moan et al. 2016; Zhou et al.

70 2016).

72 An increasing number of studies have shown that divergence can arise and be maintained due to selection imposed by heterogeneous environments despite the

74 constraining effect of gene flow (Martin et al. 2013; Morales et al. 2017). Under this scenario, divergent selection or ecologically-mediated sexual selection operating on

76 certain ("magic") traits can lead to reproductive isolation, and incompatibilities in a few "speciation genes" may be enough to constrain the homogenizing effect caused by

78 gene flow even at an early stage of speciation (Fitzpatrick et al. 2015; Nosil \& Schluter 2011; Slatkin 1973). For instance, different host plant preferences result in different

80 digestive and physiological traits in Timema walking-stick insects (Nosil 2007). Locally-adapted phenotypes in body size are related to swimming and foraging

82 ecology in guppies (Poecilia reticulata), which can maintain population diversification in the face of extensive gene flow (Fitzpatrick et al. 2015). Though evidence of

84 speciation with gene flow is accumulating (Martin et al. 2013; Morales et al. 2017; Schluter 2009; Seehausen et al. 2014), to what extent a balance between selection

86 and gene flow can drive divergence remains largely unknown. This might be interesting in populations with high propensity of range-wide gene flow such as in 
waterfowl (e.g. Liu et al. 2012) and shorebirds (Eberhart $\square$ Phillips et al. 2015; Küpper et al. 2012).

90

Shorebirds are a group of migratory species with remarkable movement ability.

92 Seasonal migration may increase the probability of individual dispersal between populations (Arguedas \& Parker 2000; Procházka et al. 2011) and consequently drive

94 frequent gene flow between geographically distant populations (Peters et al. 2012; Winker et al. 2013). Direct evidence using tracking approaches confirmed that extremely long-distance gene flow can be mediated through individual movements among remote breeding colonies of pectoral sandpipers (Calidris melanotos)

98 (Kempenaers \& Valcu 2017). Range-wide phylogeographic studies also revealed extensive gene flow in several migratory shorebird species (e.g. Trimbos et al. 2011;

100 Küpper et al. 2012; Miller et al. 2014). This may result in weak genetic structure across a species and consequently prevent population-level divergence (Eberhart $\square$ Phillips et 102 al. 2015; Jackson et al. 2017).

104 In this study, we test the role of ecology and gene flow on the divergence of two shorebird species, the Kentish Plover (Charadrius alexandrinus) and the white-faced

106 Plover (C. dealbatus) (Figure 1) . C. alexandrinus breeds in coastal areas and inland lakes in Europe, Asia and North Africa (del Hoyo et al. 2016). A previous study

108 uncovered low genetic differentiation of $\mathrm{C}$. alexandrinus across the Eurasian continent, and also between continental and island populations in East Asia (Küpper et al. 2012).

110 C. dealbatus was formerly regarded as a subspecies of Kentish plover (Hartert \& Jackson 1915; Swinhoe 1870). Breeding sites of $C$. dealbatus were documented along

112 the coast of China from Fujian to Hainan Island, and in south middle Vietnam (BirdLife International 2016), yet its geographic range is uncertain (Kennerley et al. 2008).

114 Previous studies have found subtle but diagnosable differences in morphometric, plumage and behavioral traits between the two taxa (Figure 1d), leading to the erection 116 of $C$. dealbatus as a full species (Bakewell \& Kennerley 2008; Kennerley et al. 2008; Rheindt et al. 2011). The first genetic investigation on the relationship between these 
118 two taxa provided no evidence of genetic differentiation and concluded that these species may only differ in a few genomic regions (Rheindt et al. 2011). Although based on a handful of genetic loci, this finding is noteworthy as it raises a probability of divergence in the face of gene flow between these two young species.

Here we provide comprehensive data from multiple sources to explore divergence

124 patterns between these two species of plovers. We carried out extensive sampling on breeding populations covering the potential area of contact along the Chinese coast.

126 We obtained genetic polymorphism data from multiple markers with various mutation rates, i.e. mitochondrial DNA, exons and autosomal microsatellites. Using these new

128 datasets, it is possible to estimate the intensity and direction of gene flow (Hey \& Nielsen 2004; Won \& Hey 2005) as well as other important demographic parameters

130 such as the effective population size $(\mathrm{Ne})$ and the timing of divergence (reviewed in Hey 2006) between $C$. alexandrinus and $C$. dealbatus. Because it is difficult to directly

132 quantify divergent selection, inference from the comparisons of traits which are potentially targets of selection are necessary to offer hints on selective mechanisms in

134 maintaining divergence (Hoskin \& Higgie 2010; Lande 1982; Nosil 2007). By collecting data on morphology, diet, and environmental niche, we attempt to 1) characterize

136 geographic variation in genetic and phenotypic traits in the two plovers, 2) estimate demographic history and intensity of gene flow, and 3) infer the role of multiple factors,

138 i.e. geographical premating isolation and gene flow during divergence between these two taxa. Taken together, our investigation provides new insights into the evolutionary history of two incipient bird species.

\section{MATERIALS AND METHODS}

\section{DNA sample collection}

144 We mainly collected samples along the eastern coastal area of China (Fig 1a), and also obtained samples from the two biggest continental islands, Taiwan and Hainan,

146 as well as two small islands that are close to the Chinese coastal line (Zhoushan and 
Jinmen). Sampling sites were separated by approximately $200-250 \mathrm{~km}$ along a 2,300

$148 \mathrm{~km}$ transect, spanning almost the entire Chinese coastline. Further, one high altitude population (breeding at 3350 m a.s.l.) near Qinghai Lake was sampled as an inland outgroup. Breeding individuals were captured using a funnel-trap method described in Székely et al. (2008) between March and July in 2014-2015. For each nest, blood

152 samples of the breeding pair or a chick were collected. Tissue samples were also obtained from dead individuals found in the field. Species identification during

154 sampling was based on the summary of plumage characters, morphometric, and ecological differences between C. alexandrinus and C. dealbatus, as described in

156 Kennerley et al. (2008). Overall, we collected samples from 454 individuals from 19 breeding sites. All bird-capture and sampling were performed with permission from the 158 respective authorities (Mainland China: Beijing Normal University to PJQ and Sun Yat-sen University to YL; Taiwan: Changhua County Government, New Taipei City

160 Government and Kinmen County Government to ZYJ).

\section{Morphometric analysis}

For each adult individual, four basic morphometric measurements were taken: body

164 mass, wing length, tarsus length and bill length. Body mass was measured with an electronic scale $( \pm 0.01 \mathrm{~g})$. Wing length (flattened) was measured with a wing ruler $( \pm 1$

$166 \mathrm{~mm}$ ). Bill length to skull and tarsus lengths were measured using vernier callipers $( \pm$ $0.01 \mathrm{~mm}$ ). Measurements were taken by $\mathrm{QH}, \mathrm{PJQ}$ and ZYJ following the standard

168 described in Redfern \& Clark (2001). To avoid potential biases, some individuals were measured twice or three times among these authors to make sure there was no

170 significant difference ( $p<0.05$, between $20-30$ trails) among them at the beginning and end of the fieldwork in the year 2014-2015.

We carried out principle component analysis (PCA) for the four traits to visualize the

174 variation of morphometric data. Analyses of covariance (ANCOVAs) were conducted based on the PCA results to test statistical significance. We carried out t-tests between

176 species for each measurement. Pairwise morphological difference $Q_{S T}$ based on PC1 
scores from PCA were calculated following Storz (2002) and plotted against linear distances between coastal populations. All aforementioned analyses were performed in PAST 3.12 (Hammer et al. 2001).

180

\section{DNA Sequencing and microsatellite genotyping}

182 We extracted genomic DNA using Tiangen Blood \& Tissue Genome DNA Kits, following manufacturer protocols (Tiangen, Beijing, China). DNA quality was measured

184 with NanoDrop 2000 (Thermo Scientific, USA). Three mtDNA loci, partial ATPase subunit 6/8, partial D-Loop of the mitochondrial control region (CR) and NADH

186 dehydrogenase subunit 3 fragment (ND3), were amplified for all samples using primers from Rheindt et al. (2011). PCR reactions for mtDNA amplification were carried out in

$18820 \mu$ l volumes containing 1X PCR buffer (Takara Shuzo, Japan), 10-50ng DNA template, 0.5 unit Taq DNA Polymerase (Takara Shuzo, Japan), $1.0 \mu \mathrm{M}$ of each primer,

$1902.0 \mathrm{mM}$ of each dNTP and $1.0 \mu \mathrm{M} \mathrm{MgCl}_{2}$. We also sequenced 14 autosomal and two Z-linked exonic loci (designed from Liu et al. 2018) for a subset of 40 individuals

192 representing both species and several populations within species. PCR for nuclear loci had higher concentration of dNTP at $4.0 \mathrm{mM}$ and $2.5 \mu \mathrm{M}$ for $\mathrm{MgCl}_{2}$ and PCR cycling

194 profiles are listed in Table S3. Each PCR product was checked on a 1\% agarose gel and then sequenced on ABI3730XL (Applied Biosystems, USA) served by MajorBio,

196 Shanghai, China.

198 We genotyped all individuals at 22 autosomal microsatellite markers (mst) mostly from Küpper et al. (2007) but with C204 from Funk et al. (2007) and Hru2 from Primmer et al.

200 (1995). Microsatellite loci were amplified using three multiplex PCRs with respective cycling profiles (Table S3). Each PCR was in a total volume of $15 \mu$ l containing $1 \mathrm{X}$

202 HotStart buffer (Tiangen), 10ng DNA template, 1 unit Multi HotStart DNA Polymerase (Tiangen), $0.4 \mu \mathrm{M}$ of each fluorescently labeled primer, $2.0 \mathrm{mM}$ of each dNTP and 2.0

$204 \mu \mathrm{M} \mathrm{MgCl}_{2}$. Multiplex PCR products and associated genotypes were isolated on ABI3730XL (Applied Biosystems, USA) served by Invitrogen, Shanghai, China and 
206 their length was determined using GeneMapper software v.3.7 (Applied Biosystems) against an internal size standard (GeneScan-500LIZ; Applied Biosystems).

\section{Genetic diversity and population structure analyses}

210 For DNA sequence data, we aligned each mitochondrial or nuclear locus using the CLUSTAL W algorithm implemented in MEGA v.6.06 (Tamura et al. 2013), and the

212 alignment was checked by eye and manually edited if needed. For nuclear DNA sequence data, we first used PHASE 2.1.1 (Stephens et al. 2001) to reconstruct

214 haplotypes of nuclear sequences with heterozygous sites. Each run was set to 10,000 iterations, 100 burn-in and 10 thinning intervals. For both mtDNA and nuclear loci,

216 basic genetic polymorphism statistics such as haplotype number $h$, haplotype diversity $H d$, number of segregating sites $S$, nucleotide diversity $\pi$ and Tajima's $D$ (Tajima 1989)

218 of each locus and each population were calculated in DnaSP 5.10.1 (Librado \& Rozas 2009). Haplotype networks of each locus were constructed using a median-joining

220 algorithm (Bandelt et al. 1999) in PopART 1.7.2 (Leigh \& Bryant 2015).

222 We used FreeNA (Chapuis \& Estoup 2007) to check for the frequency of null alleles at each microsatellite locus. Further tests for Hardy-Weinberg equilibrium and pairwise

224 linkage disequilibrium (LD) were carried out with Arlequin 3.1.1 (Excoffier et al. 2005). Hardy-Weinberg equilibrium tests were run with 10,000 permutations. LD tests were

226 run for 100,000 steps of Markov chain. To obtain genetic diversity estimates, we calculated observed heterozygosity $\left(H_{0}\right)$ and expected heterozygosity $\left(H_{\mathrm{E}}\right)$ in GenAIEx

$228 \quad 6.5 .1$ (Peakall \& Smouse 2012).

230 We estimated population structure between species and among sampling sites within species using several approaches. First, for mtDNA and microsatellites, we performed

232 analyses of molecular variance implemented (AMOVAs) in Arlequin to assess the proportion of genetic variance explained by the different partition settings, e.g. (1) the

234 two species, (2) C. alexandrinus continental populations and Taiwan island populations, C. dealbatus, (3) coastal populations (including Hainan Island), Qinghai 
236 and Taiwan. Second, we also calculated pairwise $\Phi_{\mathrm{ST}}$ and $F_{\mathrm{ST}}$ between breeding sites for mtDNA and mst, respectively, and we derived significance levels using 10,000

238 permutations in Arlequin.

240 For microsatellite genotypes only, we carried out assignment analyses with two model-based Bayesian approaches. First, we performed a Bayesian clustering

242 analysis using the admixture model with correlated allele frequencies implemented in STRUCTURE 2.3.4 (Hubisz et al. 2009; Pritchard et al. 2000). Ten independent

244 analyses were run from $K=1$ to $K=8$ for 500,000 Markov chain Monte Carlo (MCMC) generations with 100,000 burn-in. Replicate runs were combined using STRUCTURE

246 Harvester 0.6.94 (Earl 2012) and CLUMPP 1.1.2 (Jakobsson \& Rosenberg 2007). The most likely number of genetic clusters was also determined using Structure Harvester 248 using the criteria described in Evanno et al. (2005). Second, we used a Bayesian clustering algorithm that takes the geographical coordinates of each sampling site into

250 account using the R package GENELAND 4.0 (Guillot et al. 2005). 1,000,000 MCMC iterations were run with thinning set to 100 from 1 to 10 populations, with maximum

252 rate of Poisson process set to 100 , uncertainty of spatial coordinates set to 0 , maximum number of nuclei in the Poisson-Voronoi tessellation to 300 , and

254 independent Dirichlet distribution model for allele frequencies. With the same package, the most likely number of clusters was determined based on their posterior density. To

256 confirm the consistency of the results, we repeated the MCMC simulation 10 times.

258 Furthermore, to determine the probability that an individual was a hybrid or a migrant, we estimated the posterior probability of each individual based on multilocus

260 genotypes. First we used HYBRIDLAB 1.0 (Nielsen et al. 2006) to simulate 100 individuals of each species, F1, F2 and back-crosses in each direction from

262 microsatellite genotypes of 260 individuals with q-value higher than $95 \%$ in STRUCTURE analysis. 100 simulated parents from each species and $100 \mathrm{~F} 1$ were

264 used to calculate the threshold for individual hybrid assignment in STRUCTURE following Vähä and Primmer (2006). Finally, NewHybrid 1.1 (Anderson \& Thompson 
266 2002) was used to identify potential hybrid individuals. 100,000 burn-in followed by 400,000 sweeps were performed for both simulated and real data.

\section{Demographic analysis}

270 To infer the demographic histories of the two plover species, we applied Isolation with Migration model (IM) (Hey \& Nielsen 2007) analyses using the combined sequence

272 data set of 16 nuclear and three mtDNA loci based on 20 individuals of each species. IM analysis allows the inference of genealogies under different demographic scenarios

274 and estimation of population genetic parameters, such as divergence times, effective population sizes and migration rates between species since their divergence from the

276 common ancestor. The homologues Killdeer Charadrius vociferus sequences from GenBank were used as outgroup. The substitution rate of each locus was calculated

278 using the method in Li et al. (2010). The ratio of net genetic distance of each locus across ingroup-outgroup was calculated, compared with net distance of mitochondrial

280 cytochrome $\mathrm{b}($ cytb) and then multiplied by the substitution rate for cytb $(0.0105 \pm$ 0.0005 substitution/site/mya, Weir \& Schluter 2008). We used the Phi test (Bruen et al.

282 2006) for recombination within nuclear loci and no recombination was detected. We implemented models in IMa2p (Sethuraman \& Hey 2016), the parallel version of IMa2

284 (Hey 2010). For each analysis, we ran 48 MCMC chains for 2,500,000 steps of burn-in followed by 500,000 genealogies saved, each recorded after 100 steps. Because IM

286 analysis only provides estimates of average gene flow since the divergence of the two species, we used a Bayesian analysis in BayesAss 3.0.4 (Stephens \& Donnelly 2003)

288 based on microsatellite genotypes to characterize the level of gene flow within recent generations. We performed 10,000,000 iterations and 1,000,000 burn-in.

\section{Ecological niche modeling and niche overlaps}

292 To infer potential past range shifts induced by climatic changes, we carried out ecological niche modeling (ENM) using Maxent 3.3.3k (Phillips et al. 2009). The

294 occurrence records of the two species of plovers were obtained from online databases of the Global Biodiversity Information Facility (GBIF, http://www.gbif.org/), China Bird 
296 Report (http://www.birdreport.cn) and our records during the sampling expeditions.

Further, eight bioclimatic variables (i.e., the mean diurnal range, isothermality,

298 minimum temperature of the coldest month, mean temperature of the warmest quarter, annual precipitation, precipitation of the driest month and precipitation seasonality)

300 were obtained from the WorldClim database v.1.4 (Hijmans et al. 2005).

302 To explore niche similarity between the two species, we performed an ordination null test of PCA-env in environmental (E)-space (Broennimann et al. 2012; Hu et al. 2016).

304 The PCA-env calculates the occurrence density and environmental factor density along environmental (principal component) axes for each cell using a kernel smoothing

306 method and then uses the density of both occurrences and environmental variables to measure niche overlap along these axes (Broennimann et al. 2012). An unbiased

308 estimate of Schoener's D metric was calculated for our data using smoothed densities from a kernel density function to measure niche overlap between the two species that

310 is ensured to be independent of the resolution of the grid. Statistical confidence in niche overlap values was then tested through a one-sided niche-similarity test

312 (Broennimann et al. 2012). All statistical analyses were performed in R 3.0.2 ( $R$ Development Core Team 2013) using scripts available in Broennimann et al. (2012).

314 Details of ENM construction and niche-similarity tests are available in Appendix S1.

\section{Dietary niche differentiation inferred by stable-isotope analysis}

Because stable isotopic compositions of consumer tissues can be used to estimate the

318 relative contribution of assimilated dietary sources (DeNiro \& Epstein 1978), stable-carbon $(\mathrm{C})$ and nitrogen $(\mathrm{N})$ isotope analysis is widely used as a tool to study

320 avian dietary patterns (Hobson \& Clark 1992; Pagani-Núñez et al. 2017). Carbon isotope ratios differ between $\mathrm{C} 3, \mathrm{C} 4$ and $\mathrm{CAM}$ plants due to differences in the

322 photosynthetic pathways, and these differences are incorporated into an animal when the plants are consumed and so can be used to infer information about dietary niches

324 (Hobson \& Clark 1992). $\mathrm{N}$ isotopes are useful for identifying species/individuals which occupy different trophic positions (high $\delta^{15} \mathrm{~N}$ implies higher trophic level; Chen et al.

326 2017). In order to compare dietary differences based on differences in $\delta^{15} \mathrm{~N}$ and $\delta^{13} \mathrm{C}$ between the two species, we collected the outer pair of rectrices from seven adults per 328 site at eight sites: Qinghai Lake, Tangshan, Lianyungang and Rudong for $C$. 
alexandrinus; Fuzhou, Shanwei, Zhanjiang, Dongfang for $C$. dealbatus. Since both species perform a complete post-breeding molt within their breeding grounds (Ginn \& Melville 1983, personal observation), isotope ratios represent trophic level and habitat preferences during the breeding period. We estimated niche width and overlap per species using an isotopic Bayesian approach based on $\delta^{13} \mathrm{C}$ and $\delta^{15} \mathrm{~N}$ profile. Detailed

334 information on lab procedures and statistical analyses can be found in Appendix S2.

\section{RESULTS}

\section{Morphological differentiation}

338 The two plover species showed subtle but significant differences for most morphological traits (ANCOVA; $p<0.001$, Figure 1) even though there was

340 considerable overlap in morphology between the species at the level of the individual (Figure 1f). On average, $C$. dealbatus had a longer bill $(17.91 \pm 0.94 \mathrm{~mm}$ vs. $16.69 \pm$

$3421.06 \mathrm{~mm}$ in $C$. alexandrinus, $p<0.001$, Figure $1 \mathrm{~b})$, longer wings $(118.58 \pm 2.90 \mathrm{~mm}$ vs. $115.59 \pm 3.02 \mathrm{~mm}$ in $C$. alexandrinus, $p<0.001$, Figure $1 \mathrm{c}$ ), and larger body mass

344 (48.99 $\pm 3.26 \mathrm{~g}$ vs. $47.56 \pm 3.73 \mathrm{~g}$ in C. alexandrinus, $p=0.001$, Figure $1 \mathrm{~d}$, Table S5) than those of $C$. alexandrinus. There was no difference in tarsus length between the

346 two species $(p=0.962)$. Individuals of $C$. alexandrinus from Taiwan Island were heavier than continental populations of $C$. alexandrinus and $C$. dealbatus (both $p<$

348 0.001). $Q_{S T}$ between coastal populations of $C$. alexandrinus and C. dealbatus was negatively correlated with geographic distance $\left(R^{2}=0.293, p<0.001\right.$, Figure $\left.1 \mathrm{~g}\right)$.

\section{Genetic diversity and population structure}

352 We sequenced 357 individuals at all three mtDNA loci (224 C. alexandrinus and 133 C. dealbatus, GenBank Accession No. xxxx-xxxx). For each site, sample size ranged

354 from 11 to 30 individuals. For each individual, we obtained in total 1729 base pairs (bp) of mtDNA sequence, including 846 bp ATPase6/8, 505 bp D-loop and 378 bp ND3. $C$.

356 alexandrinus showed higher intraspecific genetic diversity than C. dealbatus (Table 1). Haplotype networks show that in all loci, most individuals were sorted into two major 
358 haplogroups, corresponding to the two species of plovers. One non-synonymous substitution separated the two haplogroups at both ATPase6/8 and ND3 loci (Figure

360 2a). Moreover, a subset of samples containing 20 individuals of each species were sequenced at 16 loci (range 440-902 bp for each locus; Table 1 and Table S1,

362 GenBank Accession No. xxxx-xxxx) for a total of 11,209 bp nuclear DNA sequence. The haplotype networks from autosomal and Z-linked loci did not show strong patterns

364 of lineage sorting like mtDNA. The most common haplotypes were shared by both species of plover (Figure $2 \mathrm{~b}$ and S1). Moreover, both species showed the signal of

366 recent demographic expansion as detected by significant Tajima's $D$ values (Table 1 ).

368 Overall genetic differentiation was significant and high in mtDNA data $\left(\Phi_{\mathrm{ST}}=0.506, p\right.$ $<0.001)$ and low at microsatellite loci $\left(F_{\mathrm{ST}}=0.036, p<0.001\right)$. For nuclear sequence

370 data, genetic differentiation between species was also significant at autosomal loci $\left(\Phi_{\mathrm{ST}}=0.100, p<0.001\right)$ and particularly high at the Z-linked loci Z4 $\left(\Phi_{\mathrm{ST}}=0.726, p<\right.$

$3720.001)$ and $Z 6\left(\Phi_{\mathrm{ST}}=0.309, p<0.001\right.$, Table S3). In the AMOVA analysis, we observed the largest difference between groups when the data were partitioned by species (i.e.

374 C. alexandrinus and C. dealbatus), with this grouping explaining $49.7 \%$ of the variance in mtDNA and $2.4 \%$ in the microsatellites $(p<0.001$; Table 2$)$. These were significantly 376 higher than the values of genetic variation when we partitioned samples as coastal vs. island populations or coastal population vs. Qinghai vs. Taiwan populations. Within $C$. 378 alexandrinus, minor genetic differentiation was found between the inland population (Qinghai Lake) and coastal populations (mtDNA $\Phi_{\mathrm{SC}}=0.042, p=0.022 ; \mathrm{mst} F_{\mathrm{SC}}=$

$380 \quad 0.021, p<0.001)$. C. alexandrinus populations on Taiwan Island also shared haplotypes with other coastal populations $\left(\operatorname{mtDNA} \Phi_{\mathrm{SC}}=0.021, p=0.146\right)$; but were

382 significantly differentiated in microsatellites (microsatellite $F_{\mathrm{SC}}=0.016, p<0.001$ ).

384 For microsatellite loci, 18 out of 22 markers were successfully genotyped. However, four markers (Calex-04, 08, 19, C204) showed a large proportion of missing data, while 386 another four loci (Calex-11, 24, 26, 43) showed an estimated frequency of null alleles over $10 \%$ and moreover one locus (Calex-35) showed H-W disequilibrium (Table S2). 
388 Consequently, the aforementioned nine loci were removed from the dataset, making genotypes at 13 loci of 402 (271 C. alexandrinus and 131 C. dealbatus) individuals for

390 the final microsatellite dataset for further analysis.

392 The results of the STRUCTURE analysis clearly showed two genetic clusters representing each species (Figure 2d) and no obvious gradual transition along the

394 coastline that could be expected from a hybrid zone. The average Delta $K$ value when $K=2$ was much higher than other options (Figure S2). Using georeferenced data in

396 GENELAND, our results corroborated the genetic clustering patterns inferred from STRUCTURE. The posterior probability was 0.70 when $K=2$ in contrast with the

398 posterior probability of 0.25 when $K=3$. We visualized the GENELAND results in a map with the probability distribution of posterior mode of class membership, which

400 further supports the separation between $C$. alexandrinus and $C$. dealbatus along the China coast (Figure 2c). The divide between these two species was located between

402 Wenzhou and Fuzhou according to the GENELAND results, but it is unclear if these two species come into contact or forms a putative hybrid zone in this region. Again, the

404 individuals from the sites in Taiwan were assigned to the cluster of $C$. alexandrinus (Figure 2c).

406

\section{Demographic history in two plovers}

408 Isolation with migration analyses suggested that $C$. alexandrinus and $C$. dealbatus diverged $0.56(0.41-5.19)$ million years ago. Estimated migration rates in both

410 directions were significant $(p<0.001)$ with slightly higher gene flow from $C$. alexandrinus into $C$. dealbatus (2.69 migrants per generation) than the vice versa (ca.

412 two migrants per generation). The estimated effective population size of $C$. alexandrinus ( $\mathrm{N}_{\mathrm{e}} \approx 1.59-4.44$ million) was about 8-10 times higher than for $C$.

414 dealbatus $\left(\mathrm{N}_{\mathrm{e}} \approx 0.15-0.52\right.$ million).

416 The estimation of recent gene flow between the two species with BayesAss using microsatellites also suggested bidirectional gene flow. Gene flow from C. dealbatus to 
418 C. alexandrinus was slightly higher $(0.013, p=0.028)$ than that in the other direction $(0.010, p=0.028)$. In C. alexandrinus populations, one likely migrant from C. dealbatus

420 and two hybrid F1 individuals were identified (probability higher than 0.5). With the same threshold value, two migrants and one F1 individual were identified in $C$.

422 dealbatus populations.

\section{The detection of hybrid individuals}

Analyses with NewHybrids provided no evidence of a large number of hybrids or a

426 higher frequency of these near the potential contact area between the species. Based on the STRUCTURE results and simulations, the optimal threshold for distinguishing

428 hybrids from non-hybrids was $\mathrm{q}=0.836$. Based on this threshold, $81.9 \%$ of the individuals (204 out of 246) collected from sites at the northern Chinese coastline,

430 Qinghai Lake and Taiwan Island were assigned to $C$. alexandrinus (Figure 2c-d). Individuals with intermediate q-values, which were possibly hybrids, were found at

432 most northern Chinese sampling sites (Figure 2d). For the southern coastline in China, 145 out of 156 Individuals (92.9\%) belonged to $C$. dealbatus with a probability larger

434 than 0.836 (Figure 2c-d). Only one individual of each species was assigned to the genetic cluster representing the other species with high probability (Figure 2d).

The result of NewHybrids was highly concordant with STRUCTURE results and

438 suggested migrants moving in both directions. NewHybrids consistently identified three migrants mentioned above with probability higher than 99\%. However,

440 NewHybrids failed to identify simulated hybrid individuals and recognized them as migrants. Thus, the result of NewHybrids was not used for hybrid identification (Fig 442 S3).

\section{Niche modeling, projections and comparisons}

Our ecological niche models effectively captured the current distribution of both $C$.

446 alexandrinus and C. dealbatus (Figure 4) with a high discrimination capacity (AUC values $>0.88$ for training and test data). Jackknife tests on variable importance for $C$. 
448 alexandrinus revealed that isothermality, precipitation seasonality and mean temperature of the warmest quarter were the three highest ranked variables when

450 used in isolation. For $C$. dealbatus, mean diurnal range and annual precipitation were the most important variables. The simulation of the three periods, i.e. Last Interglacial

452 (LIG, 120-100Ka), Last Glacial Maximum (LGM, 21Ka, MIROC model) and current times, respectively, showed range shifts in both species. In particular, these results

454 suggest that ranges of both species shrank during the LIG in the Chinese coastal area accompanied by an increase of climatic suitability in the inland region for $C$.

456 alexandrinus. In contrast, suitable habitats expanded for both species during the LGM in the coastal area, the East China Sea and the northern part of the South China Sea

458 (sea area between Hainan and Taiwan), probably due to the fall of the sea level.

460 The ordination approach using PCA-env suggested that the overlap of the current climatic niches of the two species is relatively low (Figure S4a-b). The two species can

462 be separated based on the first two PCs with an accumulative $81.5 \%$ of the total variance explained (Figure S4c). The niche equivalency test rejected the null

464 hypothesis that the species pair is distributed in identical environmental space $(p=$ 0.019; Figure S4d).

466

\section{Stable-isotope analysis}

468 Our stable-isotope analysis showed that $C$. dealbatus exhibited significantly higher $\delta^{15} \mathrm{~N}$ values than $C$. alexandrinus ( $p<0.001$, Figure 5a, Figure S5). In contrast, we did

470 not find significant differences in $\delta^{13} \mathrm{C}$ between the two species $(p=0.161)$. Further isotope space overlap analysis showed that $C$. alexandrinus individuals had a high

472 probability to be found within the isotopic niche space of $C$. dealbatus (95.3\%), while $C$. dealbatus individuals showed a relatively low probability to be found in the isotopic

474 niche space of $C$. alexandrinus (46.5\%, Figure 5b). Moreover, we found that $C$. alexandrinus showed higher variability in $\delta^{15} \mathrm{~N}$ profile across breeding populations than 476 C. dealbatus.

\section{DISCUSSION}


Our genetic data show that $C$. alexandrinus and $C$. dealbatus have diverged to a level

480 of advanced sorting of alleles between the two species particularly in mtDNA and Z-linked genes with lower effective population sizes (Figure 2a-b). For autosomal

482 microsatellite data, we also found that genetic differentiation is low at intraspecific level but substantially high between the species (Figure 2c-d, Table 2). Though it is unclear

484 whether a narrow hybrid zone exists in the contact area on the Chinese coast, a considerable level of symmetric gene flow occurred between the two plovers (Table 3).

486 We find diagnosable differences in morphometric traits and ecological characters between the two plovers along the coast. At odds with these results, a previous work

488 found no evidence of genetic differentiation between the two plovers (Rheindt et al. 2011). The present dataset comprises of systematically sampling along the Chinese

490 coast, a larger suite of genetic markers and well-characterized ecological traits (Figure 1) while Rheindt et al. (2011) analyzed samples collected outside the breeding season.

492 Potentially erroneous species assignment of non-breeding birds may underestimate genetic differentiation, because the distinguishing features in non-breeding plumage

494 are relatively subtle (Bakewell \& Kennerley 2008; Kennerley et al. 2008; Rheindt et al. 2011) and non-breeding $C$. alexandrinus and $C$. dealbatus mix frequently on the coast 496 of the South China sea (own observation and Kennerley et al. 2008).

\section{Phylogeographic patterns in C. alexandrinus and C. dealbatus}

Two genetic lineages were found among breeding Charadrius plovers along the

500 Chinese coast, corresponding the northern lineage to $C$. alexandrinus and the southern one to $C$. dealbatus, respectively (Figure 1a, Table 2). The sharp genetic

502 break between the two lineages lies between Wenzhou and Fuzhou (latitude $26-27^{\circ} \mathrm{N}$ ) north of the Taiwan Strait (Figure 2c-d). Furthermore, samples from Taiwan Island

504 belong to $C$. alexandrinus but the population in Jinmen Island is affiliated with $C$. dealbatus (Figure 2c-d). This pattern likely reflects historical isolation of the two

506 species through separation by some geographical barriers at the Chinese coast during the Pleistocene climatic fluctuation periods. Divergence between the two plovers

508560,000 years ago was inferred based on IM for the two species (Table 3, Figure 3). 
This period falls into the Marine Isotope Stage 16 of the mid-late Pleistocene, during

510 which was one of the Ice Age (Railsback et al. 2015). Accordingly the divergence between the plovers was probably linked to vicariance when the coastline was

512 separated by a land-bridge raised due to the shallow sills between the East and the South China Sea (Ni et al. 2014). Charadrius plovers have originated in the Northern

514 hemisphere and then radiated to the Southern hemisphere as suggested by a recent molecular phylogeny (Dos Remedios et al. 2015). It is thereby likely that $C$. dealbatus

516 originated from $C$. alexandrinus and could have been diverging along the east China coast since the mid-late Pleistocene.

520 breeding at high latitudes (Trimbos et al. 2011; Küpper et al. 2012; Miller et al. 2014). Panmixia or weak genetic differentiation was usually suggested, most likely driven by

522 extensive gene flow. However, it seems that islands can act as a barrier to natal dispersal for the continental Kentish plovers (Küpper et al. 2012). In contrast,

524 population structures in temperate and subtropical shorebird populations are poorly documented, probably due to a low level of species diversity. To the best of our 526 knowledge, our study shows the first documented phylogeographic break in a bird species in the coastline in China. Interestingly, concordant phylogeographic patterns

528 have been described in several coastal marine taxa, such as plants (Wang et al. 2015), fishes (Ding et al. 2018; Liu et al. 2007), shellfishes (Ni et al. 2012), and crustaceans

530 (Wang et al. 2008). Though the exact splitting times are not congruent, the observed split line is at approximately $25^{\circ} \mathrm{N}$ latitude between the East China Sea and the

532 Southern China Sea (reviewed in Ni et al. 2014). This consensus pattern resulted in the hypothesis that historical factors, i.e. sea level fluctuation during the Pleistocene,

534 caused a convergent phylogeographic pattern in multiple coastal marine fauna in the marginal northwestern Pacific Ocean (Ni et al. 2014; Ding et al. 2018). Thus, our study

536 contributes a vertebrate case to the accumulating literature about this species divergence hotspot. Apart from the major role of physical barriers, comparative

538 phylogeographic studies also revealed that other abiotic factors, like ocean current and 
hydrothermal conditions, as well as species ecological characters, i.e. dispersal ability,

540 habitat preference, life-history, and population demography can also play a role in contributing to divergence of coastline fauna (Liu et al. 2007; Ni et al. 2014).

542

\section{Morphological and ecological differentiation along a latitudinal gradient}

544 The two plovers, C. alexandrinus and C. dealbatus are distributed along the Chinese coastline across a latitudinal and associated environmental gradients from temperate

546 to tropical zones. Within each species, we found a general trend that northern populations have larger values than the southern counterparts in morphometry (Figure

548 1). This pattern may be related to Bergmann's rule which states that body size of homeothermic animals is larger in colder climates than in warmer ones (Bergmann

550 1848). Populations of both plover species distributed in such a north-south gradient may benefit from an optimal temperature control (Salewski \& Watt 2017). A mutually

552 non-exclusive explanation is that the difference in morphological traits, i.e. body mass and bill length link to potential differences in resource exploitation and life history. Our

554 data show that $C$. dealbatus has a larger average body mass than $C$. alexandrinus. Body mass is a comprehensive trait reflecting nutrition assimilation, energy reservation

556 and expenditure (McNab 2009). The difference in body mass might be related to the difference in migration behavior where a lighter body mass in C. alexandrinus is

558 favored by decreased transport cost of fuel storage during migration (Alerstam et al. 2003; McWilliams \& Karasov 2001). In contrast, larger body mass in C. dealbatus, a

560 short-distance migrant or resident, may be beneficial in multiple reproduction within a single breeding season while $C$. alexandrinus produces usually only a single clutch

562 (Lin et al. in prep.). Difference in bill length may be driven by the difference in the use of food resources (Badyaev et al. 2008) but recently, the function of the bill as

564 temperature regulator also started to attract scientific attention (Tattersall et al. 2016). On the other hand, an increasing number of studies have demonstrated that birds at 566 higher latitude and in cooler environments have shorter bills (e.g. European sparrows, Johnston 1969; Australian shorebirds, Nebel et al. 2013), consistent with Allen's Rule 568 (Allen 1877). Nevertheless, we find that populations of $C$. alexandrinus in Taiwan had 
similarly large body mass and bill lengths as $C$. dealbatus populations (Figure $1 \mathrm{~b}-\mathrm{d}, \mathrm{g}$ ),

570 which are significantly larger than mainland conspecific populations. This is probably caused by phenotypic plasticity in the Taiwan population to a sub-tropical ecology and

572 resident life history, similar to the populations of $C$. dealbatus in the South China sea coast.

574

Climatic niche modelling indicates that the climatic conditions of the two species are

576 spatially separated (Figure S4). C. dealbatus is restricted to breeding sites close to the coast, particularly in warmer tropical climate. In contrast, $C$. alexandrinus has a wider

578 climatic niche, as represented by a broader climatic zone (Figure 4). This species can breed not only on temperate coasts (Que et al. 2015) but also in inland saline lake

580 shore (Cramp \& Perrins 1983), just as Qinghai Lake. In addition, our isotope analysis revealed that $C$. alexandrinus covered a wider range of isotope ratios than $C$.

582 dealbatus, but $C$. alexandrinus exploited a lower trophic range $\left(\delta^{15} \mathrm{~N}\right)$. This indicates that $C$. dealbatus probably feeds on a higher energy diet than its sister species

584 (Hobson \& Clark 1992). However, it is unclear whether such difference may result from diet preference divergence or due to differences in food resource availability

586 (McCormack et al. 2010). Taken together, these results suggest that the ecological niches of the two plovers are significantly different in several aspects, and support a

588 role for ecology in constraining range limits and perhaps habitat preference for the two shorebird species.

\section{Incipient speciation with ongoing gene flow}

592 We find evidence of incipient speciation with ongoing gene flow between the two plovers. The IM results indicate a relatively young split with considerable gene flow

594 between the two species (Figure 3 and Table 3). We suggest this is probably due to gene flow caused by secondary contact during the Pleistocene, because our niche

596 modeling analysis reveals that the ranges of the two species were expanded and consequently overlapped between the Eastern and Southern China Sea during the

598 Last Glacial Maximum (Figure 4). While our niche modeling demonstrates a cycle of 
range dynamics caused by sea-level changes, one should bear in mind that the last

600 million years witnessed multiple glaciation cycles (Taylor et al. 2014, 2015). In particular, marine oxygen isotope records designate 28 isotope stages corresponding

602 to glacio-climatic cycles in the last million years (Railsback et al. 2015). For ocean marginal and coastline taxa, this may imply that the fluctuations in sea level can lead to

604 alternation between population isolation and contact throughout their evolutionary histories. This can in turn yield significant consequences on population divergence and

606 historical demography because speciation can proceed through cycles of allopatric stages interspersed by parapatry, resulting in a diversification process characterized

608 isolation with migration (Rheindt \& Edwards, 2011).

610 Under this premise, a key question arises: after the two plovers diverged, how was their divergence maintained in the presence of ongoing gene flow? Speciation theory

612 predicts that divergence is initiated either by genetic drift or divergent selection (Lynch et al. 2016; Rundle \& Nosil 2005; Seehausen et al. 2014; Wolf \& Ellegren 2017).

614 However, genetic drift is unlikely to have been the only force to initiate divergence in the plovers for two reasons: the large effective population sizes $(\mathrm{Ne})$ and a relatively

616 high level of gene flow (Table 3). Moreover, large $\mathrm{Ne}$ and recent divergence make it unlikely that genetic drift could have led to diagnosable differences between

618 populations (Ellstrand \& Elam 1993; Lanfear et al. 2014), and gene flow directly counteracts the diverging effects of drift (García-Navas et al. 2015; Poelstra et al.

620 2014). Another possibility is that sufficient divergent selection could contribute to overcome the homogenizing effects of gene flow (Coyne \& Orr 2004; Feder et al. 2013;

622 Nosil \& Feder 2012; Wagner et al. 2012; Wolf \& Ellegren 2017). In light of this view, the "genomic islands of speciation" model was proposed to illustrate that divergent

624 selection can have effects in specific regions across the genome leading to divergence with gene flow (Feder et al. 2013; Nosil \& Feder 2012; Wagner et al. 2012; Wolf \&

626 Ellegren 2017). Data from several organisms suggest that incipient speciation can be maintained with divergence at a small number genomic regions (Martin et al. 2013; 
628 Morales et al. 2017; Nadachowska-Brzyska et al. 2013; Towes et al. 2016 but see Curickshan et al. 2014, Burri 2017).

The geographical boundary between the two plovers was ambiguously defined in

632 previous studies (Kennerley et al. 2008; Rheindt et al. 2011). Our results show that the discontinuity in genetic structuring (Figure 2c) and morphometric values (Figure 1b-d)

634 between the two species is situated at coastline between Wenzhou and Fuzhou, indicating a contact zone (Figure 2c). For incipient species, individuals may show a

636 clinal pattern of allele frequency and morphology at their contact and form a hybrid zone (Bastos $\square$ Silveira et al. 2012; Harrison 1986; Taylor et al. 2014). Our

638 STRUCTURE results revealed no obvious signs of a hybrid zone (Figure 2d), and rather indicated sporadic migrants in the respective range of the other species. One

640 possibility is that our sampling transect was not fine-grained enough to be able to discover the potential hybrid zone, which would thus be narrower than the $200 \mathrm{~km}$

642 distance between the two neighboring sampling sites. Another possibility for an apparent lack of a hybrid zone is assortative mating between the two plovers at the

644 contact (Bearhop et al. 2005). The latter explanation is supported by the fact that populations of the two species close to this region were much more divergent in

646 morphological traits than ones farther apart (Figure 1b-d). Reproductive character displacement between the two species (Brown \& Wilson 1956; Robinson \& Wilson

648 1994; Grant and Grant 2006) in the contact regions would constrain interbreeding (Rybinski et al. 2016; Winkelmann et al. 2014). Obviously, genetic data alone cannot

650 demonstrate this and detailed experiments related to assortative mating in the contact zone are required.

\section{Taxonomic implications}

654 This study offers several taxonomic implications for the $C$. alexandrinus complex in East Asia. Kennerley et al. (2008) recommended that the tropical breeding population, 656 previously defined as the subspecies dealbatus warranted species status, based on differentiation in morphology, behavior and distribution from C. alexandrinus. 
658 Uncertainty arouse about the taxonomic status because dealbatus was not distinguished from C. alexandrinus in a first genetic evaluation (Rheindt et al. 2011).

660 Our results provide further support for a pair of incipient species, indicating that $C$. dealbatus is the youngest species within the genus Charadrius (Barth et al. 2013).

662 Although we did not apply explicit Bayesian species delimitation analyses (e.g. Yang \& Rannala 2014), our results clearly demonstrate multiple diagnosable morphological

664 characters and distinct ecological niches, which are likely key factors to maintain species limits. Beyond the detection of differences between these plovers, this study

666 forms a basis for conservation considerations of $C$. dealbatus because of its restricted range and adaptation to subtropical climate, as well as a risk of population decline

668 caused by habitat loss in the China coastline (Ma et al. 2014).

670 Conclusions and perspectives

Resolving the balance between diverging selection and gene flow is of fundamental

672 importance to understand speciation processes. Here, we show that $C$. alexandrinus and $C$. dealbatus represent a case of incipient species in which divergent selection

674 associated with ecological differences likely works as efficient mechanism for the maintenance of divergence in the face of gene flow. While the full species status of $C$.

676 dealbatus may be justified, it remains untested whether a strong level of reproductive isolation has been established between $C$. alexandrinus and C. dealbatus. Further, we

678 have shown low genetic divergence between the two plovers, so it would be of particular importance to explore the patterns of divergence at the genome level and

680 determine whether specific regions are related reproductive isolation and adaptation. In addition, the IM analysis presented here estimated average historical gene flow, but

682 it would be interesting to evaluate more realistic (and complex) demographic models in order to estimate changes in $\mathrm{Ne}$ and the span of isolation and secondary contact better.

684 Genome-wide population genetic approaches promise the power for better resolved evolutionary history of the two Charadrius plovers but also open an avenue to 686 characterize the genetic architecture associated with phenotypic trait divergence and 
local adaptation (Freedman et al. 2014; Nadachowska-Brzyska et al. 2013; Towes et al.

688 2016).

690 ACKNOWLEDEMENTS

We thank Qiaoyi Liang, Xiaoyan Long, Derong Meng, Demeng Jiang, Li Tian and Hebo

692 Peng help with field sampling, Guoling Chen, Yangkai Zhou for their assistance with laboratory works. Special thanks are due Shaochong Peng for preparing sketches of

694 plovers in Figure 1.

696 Funding information:

This study was supported by National Natural Science Foundation of China,

698 Grant/Award Number: 31301875 and 31572251 to YL, 31600297 to PJQ and 31572288 to ZWZ; and the Open Grant of the State Key Laboratory of Biocontrol of

700 Sun Yat-sen University to YL and TZ (SKLBC13KF03), Youth Innovation Promotion Association CAS (2015304) to $\mathrm{JHH}$. Computational machinery time work was granted

702 by Special Program for Applied Research on Super Computation of the NSFC-Guangdong Joint Fund (the second phase) under Grant No. U1501501 to YL.

704

\section{DATA ACCESSIBILITY}

706 Sequences deposited at GenBank: accession number xxxxx-xxxxx

Phenotype, distribution, stable isotope and microsatellite genotypes available at:

708 Dryad Doi: xxx

\section{AUTHOR CONTRIBUTIONS}

Y.L., Z.W.Z. and T. S. conceived and designed the study, P.J.Q., C-Y.C., Q.H., J.M.,

712 N.Z., X.J.W., and T. S. collected data in the field, X.J.W. and S.M.L conducted molecular genetic laboratory work, X.J.W. P.J.Q. analyzed genetic data with input from

714 Y.L. and G.H.. J.H.H. performed niche modeling analysis, C.C.Z. carried out stable isotope analysis with input from E.P.-G. and C.D.. X.J.W P.J.Q. and Y.L. wrote the 
716 manuscript with input from J.H.H., G.H., X.C.Z. and C.D. All authors gave final approval for publication.

718

\section{REFERENCES}

720 Alerstam T, Hedenström A and Åkesson S (2003) Long-distance migration: evolution and determinants. Oikos, 103, 247-260.

722 Allen JA (1877) The influence of physical conditions in the genesis of species. Radical Review 1, 108-140.

724 Anderson E, Thompson E (2002) A model-based method for identifying species hybrids using multilocus genetic data. Genetics 160, 1217-1229.

726 Arguedas N, Parker PG (2000) Seasonal migration and genetic population structure in house wrens. The Condor 102, 517-528.

728 Badyaev AV, Young RL, Oh KP, Addison C (2008) Evolution on a local scale: developmental, functional, and genetic bases of divergence in bill form and associated changes in song structure

730 between adjacent habitats. Evolution 62, 1951-1964.

732

Bakewell D, Kennerley P (2008) Field characteristics and distribution of an overlooked Charadrius plover from South-East Asia. Birding Asia 9, 46-57.

Bandelt H-J, Forster P, Röhl A (1999) Median-joining networks for inferring intraspecific phylogenies.

734 Molecular Biology and Evolution 16, 37-48.

Barth JM, Matschiner M, Robertson BC (2013) Phylogenetic position and subspecies divergence of the 736 endangered New Zealand Dotterel (Charadrius obscurus). PLOS ONE 8, e78068.

738

Bearhop S, Fiedler W, Furness RW, et al. (2005) Assortative mating as a mechanism for rapid evolution of a migratory divide. Science 310, 502-504.

Beaumont MA, Zhang W, Balding DJ (2002) Approximate Bayesian computation in population genetics. Genetics 162, 2025-2035.

Bergmann C (1848) Über die Verhältnisse der Wärmeökonomie der Thiere zu ihrer Grösse.

742 Bernardi G, Alva-Campbell YR, Gasparini JL, Floeter SR (2008) Molecular ecology, speciation, and evolution of the reef fish genus Anisotremus. Molecular Phylogenetics and Evolution 48,

744 929-935.

746 occurrence and spatial environmental data. Global Ecology and Biogeography 21, 481-497.

Brown WL, Wilson EO (1956) Character displacement. Systematic Zoology 5, 49-64.

748 Bruen TC, Philippe H, Bryant D (2006) A simple and robust statistical test for detecting the presence of recombination. Genetics 172, 2665-2681.

750 Burri R (2017) Linked selection, demography and the evolution of correlated genomic landscapes in birds and beyond. Molecular Ecology 26, 3853-3856.

752 Carson H, Clague D (1995) Geology and biogeography of the Hawaiian Islands. Hawaiian Biogeography: Evolution on a Hot Spot Archipelago, 14-29.

754 Chapuis M-P, Estoup A (2007) Microsatellite null alleles and estimation of population differentiation. Molecular Biology and Evolution 24, 621-631.

756 Chen Q, Liu Y, Ho WT, Chan SK, Li QH, \& Huang JR (2017) Use of stable isotopes to understand food webs in Macao wetlands. Wetlands Ecology and Management 25, 59-66. 
758 Coyne JA, Orr HA (2004) Speciation Sinauer Associates Sunderland, MA.

Cramp S, Perrins C (1983) The Birds of Europe the Middle East and North Africa, Vol. III (Waders to

760 Gulls). Oxford University Press, Oxford. pp 153-166.

762 reduced diversity, not reduced gene flow. Molecular Ecology 23,3133-3157.

del Hoyo J, Collar N, Kirwan GMS, C.J. (2016) White-faced Plover (Charadrius dealbatus). In: del Hoyo,

764 J., Elliott, A., Sargatal, J., Christie, D.A. \& de Juana, E. (eds.). Handbook of the Birds of the World Alive. Lynx Edicions, Barcelona., retrieved from http://www.hbw.com/node/467300 on

76616 June 2018

768 species occupying the same habitat. Science 201, 906-908.

770 region of the inshore fish, Bostrychus sinensis, in the East China Sea. Heredity, 120, 51-62.

772 biogeographic origins of a globally distributed avian clade. Molecular Phylogenetics and Evolution 89, 151-159.

774 Earl DA (2012) STRUCTURE HARVESTER: a website and program for visualizing STRUCTURE output and implementing the Evanno method. Conservation Genetics Resources 4, 359-361.

776 Eberhart-Phillips L, Hoffman JI, Brede EG, et al. (2015) Contrasting genetic diversity and population structure among three sympatric Madagascan shorebirds: parallels with rarity, endemism,

778 and dispersal. Ecology and Evolution 5, 997-1010.

Ellstrand NC, Elam DR (1993) Population genetic consequences of small population size: implications

780 for plant conservation. Annual Review of Ecology and Systematics 24, 217-242.

\section{2}

Evanno G, Regnaut S, Goudet J (2005) Detecting the number of clusters of individuals using the software STRUCTURE: a simulation study. Molecular Ecology 14, 2611-2620.

784 population genetics data analysis. Evolutionary Bioinformatics 1, 47-50.

786 genomic divergence. Annual Review of Ecology, Evolution, and Systematics 44, 73-97.

Feder JL, Flaxman SM, Egan SP, Comeault AA, Nosil P (2013) Geographic mode of speciation and

Fitzpatrick SW, Gerberich JC, Kronenberger JA, Angeloni LM, Funk WC (2015) Locally adapted traits

788 maintained in the face of high gene flow. Ecology Letters 18, 37-47.

$790 \quad$ history of dogs. PLoS Genetics 10, e1004016.

Funk WC, Mullins TD, Haig SM (2007) Conservation genetics of snowy plovers (Charadrius alexandrinus)

792 in the Western Hemisphere: population genetic structure and delineation of subspecies. Conservation Genetics 8, 1287-1309.

794 García-Navas V, Bonnet T, Waldvogel D, et al. (2015) Gene flow counteracts the effect of drift in a Swiss population of snow voles fluctuating in size. Biological Conservation 191, 168-177.

796 Ginn H, Melville D (1983) Moult in birds. BTO Guide 19. British Trust for Ornithology, Tring.

Grant PR, Grant BR (2006). Evolution of character displacement in Darwin's finches. Science 313,

\section{224-226.}

Guillot G, Mortier F, Estoup A (2005) GENELAND: a computer package for landscape genetics.

$800 \quad$ Molecular Ecology Notes 5, 712-715.

Hammer $\varnothing$, Harper D, Ryan P (2001) PAST: Paleontological Statistics Software Package for education 
802 and data analysis. Palaeontolia Electronica 4.

Harrison RG (1986) Pattern and process in a narrow hybrid zone. Heredity 56, 337.

804 Hartert E, Jackson AC (1915) Notes on some waders. Ibis 57, 526-534.

Hey, J. (2006). Recent advances in assessing gene flow between diverging populations and

806 species. Current Opinion in Genetics \& Development 16, 592-596.

808 Evolution 27, 905-920.

Hey J, Nielsen R (2004) Multilocus methods for estimating population sizes, migration rates and

810 divergence time, with applications to the divergence of Drosophila pseudoobscura and $\mathrm{D}$. persimilis. Genetics $167,747-760$.

812 Hey J, Nielsen R (2007) Integration within the Felsenstein equation for improved Markov chain Monte Carlo methods in population genetics. Proceedings of the National Academy of Sciences of the United States of America 104, 2785-2790.

Hijmans RJ, Cameron SE, Parra JL, Jones PG, Jarvis A (2005) Very high resolution interpolated climate

surfaces for global land areas. International Journal of Climatology 25, 1965-1978.

Hobson KA, Clark RG (1992) Assessing avian diets using stable isotopes I: turnover of ${ }^{13} \mathrm{C}$ in tissues.

Hoskin Cl, Higgie M (2010) Speciation via species interactions: the divergence of mating traits within Condor 94, 181-188.

species. Ecology Letters 13, 409-420.

Hu J, Broennimann O, Guisan A, et al. (2016) Niche conservatism in Gynandropaa frogs on the southeastern Qinghai-Tibetan Plateau. Scientific Reports 6, 32624.

824 assistance of sample group information. Molecular Ecology Resources 9, 1322-1332.

Hubisz MJ, Falush D, Stephens M, Pritchard JK (2009) Inferring weak population structure with the

BirdLife International (2016) IUCN Red List for birds. Downloaded from http://www.birdlife.org on

$826 \quad 8 / 09 / 2016$

Jackson DU, dos Remedios N, Maher KH, et al. (2017) Polygamy slows down population divergence in 828 shorebirds. Evolution 71, 1313-1326.

Jakobsson M, Rosenberg NA (2007) CLUMPP: a cluster matching and permutation program for dealing

830 with label switching and multimodality in analysis of population structure. Bioinformatics 23, 1801-1806.

832 Johnston RF (1969) Character variation and adaptation in European sparrows. Systematic Biology 18, 206-231.

834 Küpper C, Edwards SV, Kosztolanyi A, et al. (2012) High gene flow on a continental scale in the polyandrous Kentish plover Charadrius alexandrinus. Molecular Ecology 21, 5864-5879.

836 Küpper C, Horsburgh GJ, Dawson DA, et al. (2007) Characterization of 36 polymorphic microsatellite loci in the Kentish plover (Charadrius alexandrinus) including two sex-linked loci and their

838 amplification in four other Charadrius species. Molecular Ecology Notes 7, 35-39.

$840 \quad$ polygynous shorebird. Nature 541, 528.

Kennerley PR, Bakewell DN, Round PD (2008) Rediscovery of a long-lost Charadrius plover from 842 South-East Asia. Forktail 24, 63-79.

Lande R (1982) Rapid origin of sexual isolation and character divergence in a cline. Evolution 36,

844 213-223.

Lanfear R, Kokko H, Eyre-Walker A (2014) Population size and the rate of evolution. Trends in Ecology 
846 \& Evolution 29, 33-41.

Le Moan A, Gagnaire PA, Bonhomme F (2016) Parallel genetic divergence among coastal-marine

848 ecotype pairs of European anchovy explained by differential introgression after secondary contact. Molecular Ecology 25, 3187-3202.

850 Leigh JW, Bryant D (2015) Popart: full-feature software for haplotype network construction. Methods in Ecology and Evolution 6, 1110-1116.

852 Li JW, Yeung CK, Tsai P-W, et al. (2010) Rejecting strictly allopatric speciation on a continental island: prolonged postdivergence gene flow between Taiwan (Leucodioptron taewanus, Passeriformes Timaliidae) and Chinese (L. canorum canorum) hwameis. Molecular Ecology 19, 494-507.

856 Liu JX, Gao TX, Wu SF, Zhang YP (2007) Pleistocene isolation in the Northwestern Pacific marginal seas and limited dispersal in a marine fish, Chelon haematocheilus (Temminck \& Schlegel, 1845).

858 Molecular Ecology 16, 275-288.

860 the tufted duck (Aythya fuligula). Heredity, 109, 108-116.

Liu Y, Liu S, Yeh CF, Zhang N, Chen G, Que P, ... \& Li SH. (2018). The first set of unive

862 protein-coding loci markers for avian phylogenetic and population genetic studies. bioRxiv, 272732.

864 Librado P, Rozas J (2009) DnaSP v5: a software for comprehensive analysis of DNA polymorphism data. Bioinformatics 25, 1451-1452.

866 Lynch M, Ackerman MS, Gout J-F, et al. (2016) Genetic drift, selection and the evolution of the mutation rate. Nature Reviews Genetics 17, 704-714.

868 Ma Z, Melville D S, Liu J, et al. (2014) Rethinking China's new great wall : Massive seawall construction in coastal wetlands threatens biodiversity. Science, 346, 912-914.

870 Martin SH, Dasmahapatra KK, Nadeau NJ, et al. (2013) Genome-wide evidence for speciation with gene flow in Heliconius butterflies. Genome Research 23, 1817-1828.

872 Mayr E (1963) Animal species and evolution Belknap Press of Harvard University Press Cambridge, Massachusetts.

874 McCormack JE, Zellmer AJ, Knowles LL (2010) Does niche divergence accompany allopatric divergence in Aphelocoma jays as predicted under ecological speciation?: insights from tests with niche 876 models. Evolution 64, 1231-1244.

McNab BK (2009) Ecological factors affect the level and scaling of avian BMR. Comparative

878 Biochemistry and Physiology Part A: Molecular \& Integrative Physiology 152, 22-45.

880 migratory birds and its ecological significance. Comparative Biochemistry and Physiology Part A: Molecular \& Integrative Physiology 128, 577-591.

882 Miller MP, Haig SM, Mullins TD, Ruan L, et al. (2015) Intercontinental genetic structure and gene flow in Dunlin (Calidris alpina), a potential vector of avian influenza. Evolutionary Applications, 8 , 884 149-171.

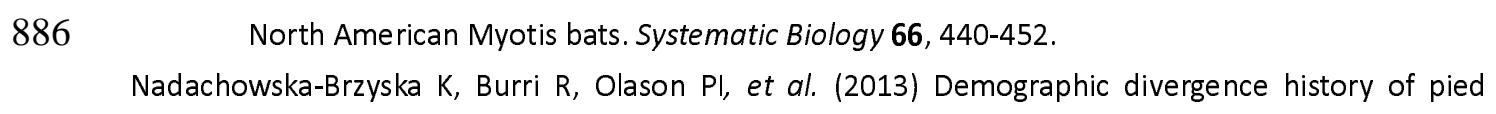
888 flycatcher and collared flycatcher inferred from whole-genome re-sequencing data. PLOS 
Genetics 9, e1003942.

890 Nadeau NJ, Whibley A, Jones RT, et al. (2012) Genomic islands of divergence in hybridizing Heliconius butterflies identified by large-scale targeted sequencing. Phil. Trans. R. Soc. B 367, 343-353.

892 Nebel S, Rogers KG, Minton CD, Rogers DI (2013) Is geographical variation in the size of Australian shorebirds consistent with hypotheses on differential migration? Emu 113, 99-111.

894 Ni G, Li Q, Kong LF, Zheng XD (2012) Phylogeography of bivalve Cyclina sinensis: testing the historical glaciations and Changjiang River outflow hypotheses in northwestern Pacific. PLOS ONE 7, e49487.

Ni G, Li Q, Kong LF \& Yu Hong (2014) Comparative phylogeography in marginal seas of the northwestern Pacific, Molecular Ecology, 23, 534-548.

Nielsen EE, Bach LA, Kotlicki P (2006) HYBRIDLAB (version 1.0): a program for generating simulated

$900 \quad$ hybrids from population samples. Molecular Ecology Notes 6, 971-973.

Nosil P (2007) Divergent host plant adaptation and reproductive isolation between ecotypes of

902 Timema cristinae walking sticks. The American Naturalist 169, 151-162.

904 R. Soc. B, 367, 332-342.

Nosil P, Schluter D (2011) The genes underlying the process of speciation. Trends in Ecology \& $906 \quad$ Evolution 26, 160-167.

Pagani-Núñez E, Renom M, Mateos-Gonzalez F, Cotín J, Senar JC (2017) The diet of great tit nestlings:

908 Comparing observation records and stable isotope analyses. Basic and Applied Ecology 18, 57-66.

910 Peakall R, Smouse PE (2012) GenAlEx 6.5: genetic analysis in Excel. Population genetic software for teaching and research--an update. Bioinformatics 28, 2537-2539.

912 Peters JL, McCracken KG, Pruett CL, et al. (2012) A parapatric propensity for breeding precludes the completion of speciation in common teal (Anas crecca, sensu lato). Molecular Ecology 21,

914 4563-4577.

Phillips SJ, Dudik M, Elith J, et al. (2009) Sample selection bias and presence-only distribution models:

916 implications for background and pseudo-absence data. Ecological Applications 19, 181-197.

Poelstra JW, Vijay N, Bossu CM, et al. (2014) The genomic landscape underlying phenotypic integrity in

918 the face of gene flow in crows. Science 344, 1410-1414.

Primmer C, Møller A, Ellegren H (1995) Resolving genetic relationships with microsatellite markers: a

920 parentage testing system for the swallow Hirundo rustica. Molecular Ecology 4, 493-498.

Pritchard JK, Stephens M, Donnelly P (2000) Inference of population structure using multilocus

922 genotype data. Genetics 155, 945-959.

Procházka P, Stokke BG, Jensen $\mathrm{H}$, et al. (2011) Low genetic differentiation among reed warbler

924 Acrocephalus scirpaceus populations across Europe. Journal of Avian Biology 42, 103-113.

Que P, Chang Y, Eberhart-Phillips L, et al. (2015) Low nest survival of a breeding shorebird in Bohai Bay,

926 China. Journal of Ornithology 156, 297-307.

$\mathrm{R}$ Development Core Team (2013) R: a language and environment for statistical computing. $\mathrm{R}$

928 Foundation for Statistical Computing, , Vienna, Austria. http://www.rproject.org/

Railsback LB, Gibbard PL, Head MJ, Voarintosa NRG, Toucanne S (2015) An optimized scheme of

$930 \quad$ lettered marine isotope substages for the last 1.0 million years, and the climatostrati-graphic nature of isotope stages and substages. Quaternary Science Reviews 111, 94-106.

932 Redfern CP, Clark JA (2001) Ringers' Manual. British Trust for Ornithology. 
Rheindt FE, Edwards SV (2011) Genetic introgression: an integral but neglected component of speciation in birds. Auk 128:620-632

Rheindt FE, Szekely T, Edwards SV, et al. (2011) Conflict between genetic and phenotypic differentiation: the evolutionary history of a 'lost and rediscovered' shorebird. PLOS ONE 6, e26995.

938 Robinson BW, Wilson DS (1994) Character release and displacement in fishes: a neglected literature. The American Naturalist 144, 596-627.

940 Rundle HD, Nosil P (2005) Ecological speciation. Ecology Letters 8, 336-352.

942 selection favoring modified dispersal patterns in a young avian hybrid zone. Evolution 70, 2226-2238.

944 Salewski V, Watt C (2017) Bergmann's rule: a biophysiological rule examined in birds. Oikos 126.

Schluter D (2009) Evidence for ecological speciation and its alternative. Science 323, 737-741.

946 Seehausen O, Butlin RK, Keller I, et al. (2014) Genomics and the origin of species. Nature Reviews Genetics 15, 176-192.

948 Sethuraman A, Hey J (2016) IMa2p-parallel MCMC and inference of ancient demography under the Isolation with migration (IM) model. Molecular Ecology Resources 16, 206-215.

950 Slatkin M (1973) Gene flow and selection in a cline. Genetics 75, 733-756.

Stephens M, Donnelly P (2003) A comparison of bayesian methods for haplotype reconstruction from

952 population genotype data. American Journal of Human Genetics 73, 1162-1169.

Stephens M, Smith NJ, Donnelly P (2001) A new statistical method for haplotype reconstruction from

954 population data. The American Journal of Human Genetics 68, 978-989.

Storz JF (2002) Contrasting patterns of divergence in quantitative traits and neutral DNA markers:

956 analysis of clinal variation. Molecular Ecology 11, 2537-2551.

Swanson HK, Lysy M, Power M, et al. (2015) A new probabilistic method for quantifying n-dimensional

958 ecological niches and niche overlap. Ecology 96, 318-324.

Swinhoe R (1870) On the plovers of the genus Aegialites found in China. Proceedings of the Zoological

960 Society London 1870, 136-142.

Székely T, Kosztolányi A, Küpper C (2008) Practical guide for investigating breeding ecology of Kentish plover.

http://www.bath.ac.uk/bio-sci/biodiversity-lab/pdfs/KP_Field_Guide_v3.pdf).

964 Tajima $\mathrm{F}(1989)$ Statistical method for testing the neutral mutation hypothesis by DNA polymorphism. Genetics 123, 585-595.

966 Tamura K, Stecher G, Peterson D, Filipski A, Kumar S (2013) MEGA6: Molecular Evolutionary Genetics Analysis version 6.0. Molecular Biology and Evolution 30, 2725-2729.

968 Tattersall GJ, Arnaout B, Symonds MR (2016) The evolution of the avian bill as a thermoregulatory organ. Biological Reviews 92, 1630-1652.

970 Taylor SA, White TA, Hochachka WM, et al. (2014) Climate-mediated movement of an avian hybrid zone. Current Biology 24, 671-676.

972 Taylor SA, Larson EL, Harrison RG (2015) Hybrid zones: windows on climate change. Trends in Ecology and Evolution 30, 398-406.

974 Trimbos K B, Musters C J M, Verkuil Y I, et al. (2011) No evident spatial genetic structuring in the rapidly declining Black-tailed Godwit Limosa limosa limosa, in The Netherlands. Conservation 
976 Genetics 12, 629-636.

Toews DPL, Taylor SA, Vallender R, Brelsford A, Butcher BG, Messer PW, Lovette IJ. (2016) Plumage

978 genes and little else distinguish the genomes of hybridizing warblers. Current Biology 26, 2313-2318.

980 Vähä J, Primmer C (2006) Efficiency of model-based Bayesian methods for detecting hybrid individuals under different hybridization scenarios and with different numbers of loci. Molecular Ecology 15, 63-72.

984 predict adaptive radiation. Nature 487, 366-369.

Wang C, Li C, \& Li S. (2008) Mitochondrial DNA-inferred population structure and demographic history

986 of the mitten crab (Eriocheir sensu stricto) found along the coast of mainland China. Molecular Ecology 17, 3515-3527.

988 Wang J, Tsang LM, Dong YW (2015) Causations of phylogeographic barrier of some rocky shore species along the Chinese coastline. BMC Evolutionary Biology 15, 114.

990 Weir JT, \& Schluter D. (2008). Calibrating the avian molecular clock. Molecular Ecology, 17, 2321-2328.

Winkelmann K, Genner MJ, Takahashi T, Rüber L (2014) Competition-driven speciation in cichlid fish.

$992 \quad$ Nature Communications 5, 3412.

Winker K, McCracken KG, Gibson DD, Peters JL (2013) Heteropatric speciation in a duck, Anas crecca.

994 Molecular Ecology 22, 5922-5935.

$996 \quad$ Nature Reviews Genetics 18, 87.

Won YJ, Hey J (2005) Divergence population genetics of chimpanzees. Molecular Biology and Evolution

998 22, 297-307.

Yang Z, Rannala B. (2014) Unguided species delimitation using DNA sequence data from multiple

$1000 \quad$ loci. Molecular Biology and Evolution 31, 3125-3135.

1002 and adaptation. Science 346, 1311-1320.

Zhou Y, Duvaux L, Ren G, et al. (2016) Importance of incomplete lineage sorting and introgression in
the origin of shared genetic variation between two closely related pines with overlapping distributions. Heredity 118, 211-220. 


\section{FIGURE LEGENDS}

1010 FIGURE 1 Sampling localities, morphology and trophic level differentiation of the Kentish Plover Charadrius alexandrinus (blue) and the White-faced Plover $C$. 1012 dealbatus (yellow).

(a) Samples were from an inland site (1, Qinghai Lake), 16 Chinese mainland coastal

1014 localities (2, Tangshan; 3, Cangzhou; 4, Weifang; 5, Lianyungang; 6, Nantong; 7, Ningbo; 8, Zhoushan; 9, Wenzhou; 12, Fuzhou; 13, Xiamen; 14, Jinmen; 15, Shanwei;

1016 16, Yangjiang; 17, Zhanjiang; 18, Beihai and 19, Dongfang), and two localities on Taiwan Island (10, Xinbei and 11, Zhanghua).

1018 (b-f) Differences between two species in several characters. C. alexandrinus has on average shorter bill length (except for Taiwan populations) (b), wing length (c) and

1020 lower body mass (except for Taiwan populations) (d) than C. dealbatus. Localities with less than five measured adults were excluded in these analyses. (f) Plots of the first

1022 two principal components and their associated variance explained which showed the subtle morphometric differences between the two species. (e) C. alexandrinus has

1024 overall more darkish plumage than $C$. dealbatus and males of the latter species have less black tinged on face and neck during breeding season. (g) Pairwise morphological

1026 difference $Q_{S T}$ plotted against geographical distance between coastal populations of $C$. alexandrinus and C. dealbatus. $Q_{S T}$ values within species were marked by blue or

1028 yellow dots. $Q_{S T}$ between species (grey circles) declined as the distance increased (regression showed as the dashed line).

FIGURE 2 Haplotype networks based on mitochondrial and nuclear DNA sequences,

1032 and population genetic structures based on microsatellite loci. C. alexandrinus marked in blue and $C$. dealbatus in yellow. (a) Haplotype networks of three mitochondrial loci.

1034 For ATPase6/8 and ND3, over 95\% of the individuals are sorted into two major haplogroups. (b) Examples of haplotype networks based on 55 to 80 individuals of four

1036 exonic nuclear loci. (c) Genetic clustering inferred with Geneland based on microsatellite genotypes. Blue and yellow show the assignment probability of a 
1038 location for alternative genetic clusters. Location numbers are consistent with Figure 1.

(d) Genetic clustering inferred with STRUCTURE using microsatellites.

1040

FIGURE 3 Posterior densities of population demographic parameters estimated using

1042 the isolation-with-migration model (IM) implemented in IMa2p. These analyses used the combined data set of three mitochondrial (1729 bp) and 15 nuclear exonic loci

1044 (11209 bp). K represents the Kentish Plover C. alexandrinus; W represents

White-faced Plover $C$. dealbatus. (a) Population divergence times ( $T$ ) of $C$.

1046 alexandrinus and C. dealbatus. (b) Population migration rates (2NM) stand for the average number of individuals in each group that were migrants from the other group in

1048 the past. Gene flow on both directions was significant. (c) Effective population sizes $(\mathrm{Ne})$ of the two species and their most recent common ancestor.

1050

FIGURE 4 Predicted environmental suitability for $C$. alexandrinus (left) and $C$.

1052 dealbatus (right), via ecological niche modeling (ENM). ENM results are shown for the Last Interglacial (LIG, 120-100Ka), Last Glacial Maximum (LGM, 21Ka, MIROC model)

1054 and current times, respectively.

1056 FIGURE 5 (a) Raw data (bottom-left), density distribution (top-left and bottom-right), and stable isotope related to dietary niche regions (top right) of $\delta^{13} \mathrm{C}$ and $\delta^{15} \mathrm{~N}$ of $C$.

1058 alexandrinus and C. dealbatus feathers generated by "nicheROVER" (Swanson et al. 2015). The niche region of C. alexandrinus (blue) was broader than and contained

1060 that of $C$. dealbatus (yellow). (b) Distribution of the posterior probability that an individual from one species is found within the niche region of the other species.

1062 Vertical lines for mean and 95\% credible intervals are included in the histogram of each overlap metric. 
bioRxiv preprint doi: https://doi.org/10.1101/406041; this version posted August 31, 2018. The copyright holder for this preprint (which was not certified by peer review) is the author/funder, who has granted bioRxiv a license to display the preprint in perpetuity. It is made available under aCC-BY-NC-ND 4.0 International license.

\section{FIGURE 1}

1066

(a)

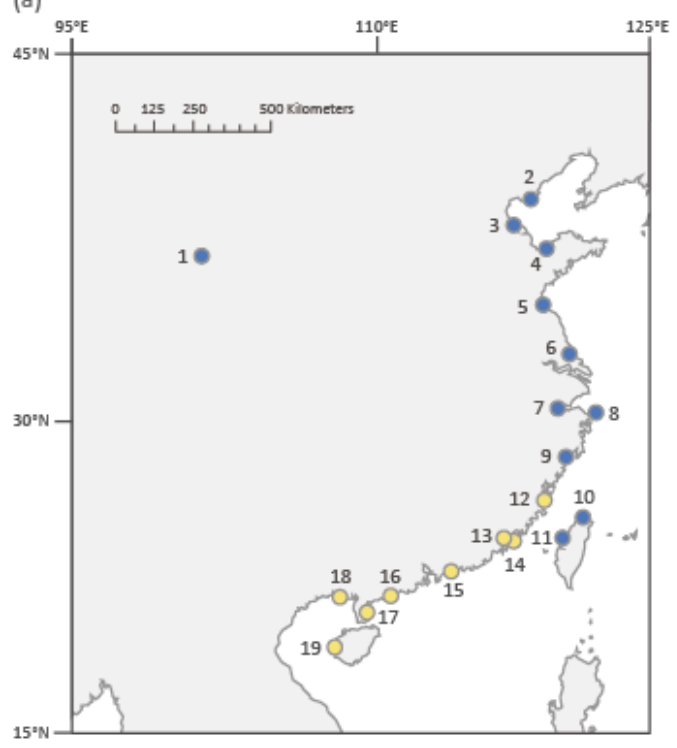

(b) Bill length

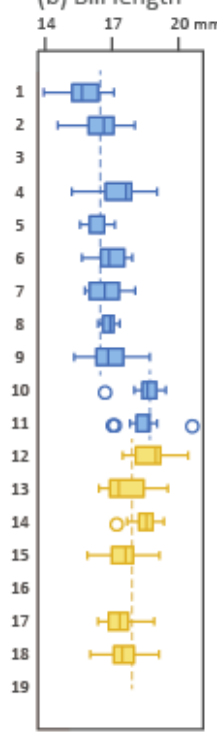

(c) Wing length

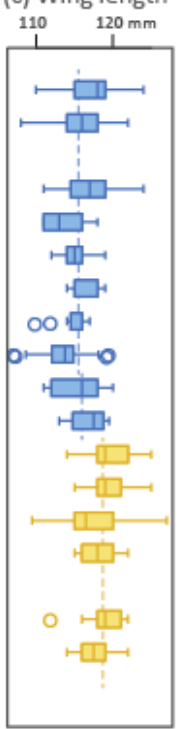

(d) Body mass

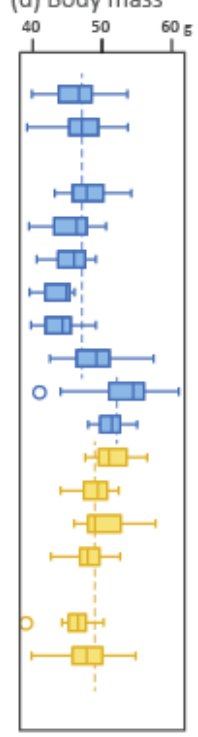

(e)

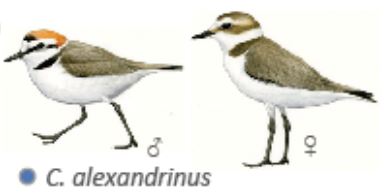

- C. alexandrinus

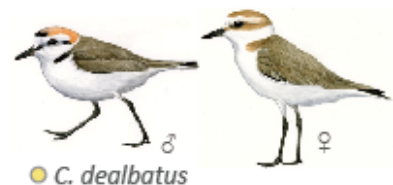

(f)

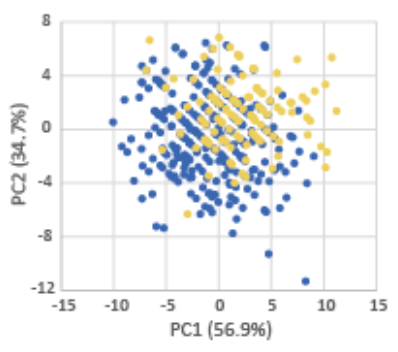

(g)

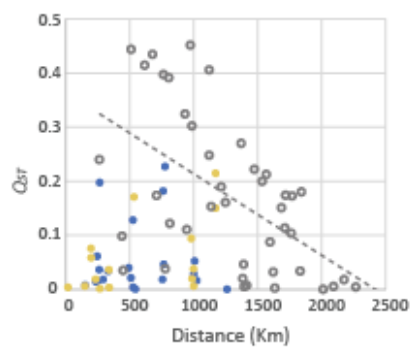


bioRxiv preprint doi: https://doi org/10.1101/406041; this version posted August 31, 2018. The copyright holder for this preprint (which was not certified by peer review) is the author/funder, who has granted bioRxiv a license to display the preprint in perpetuity. It is made available under aCC-BY-NC-ND 4.0 International license.

\section{FIGURE 2}

(a)
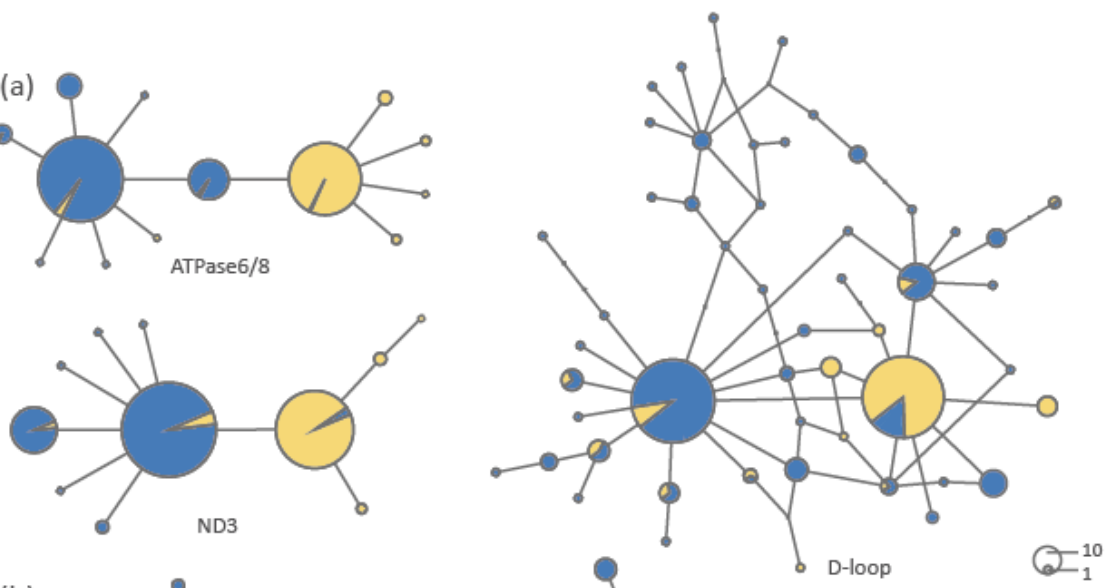

(b)
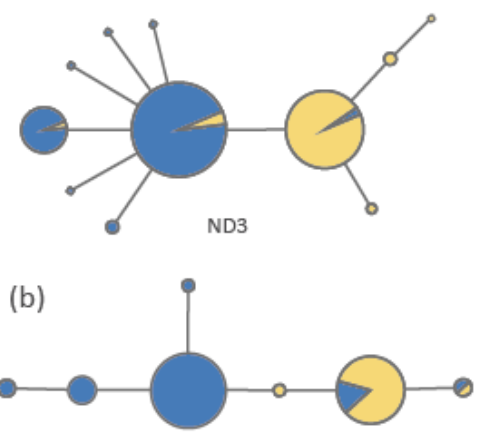

Z4

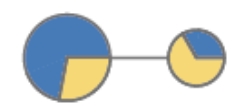

Z6
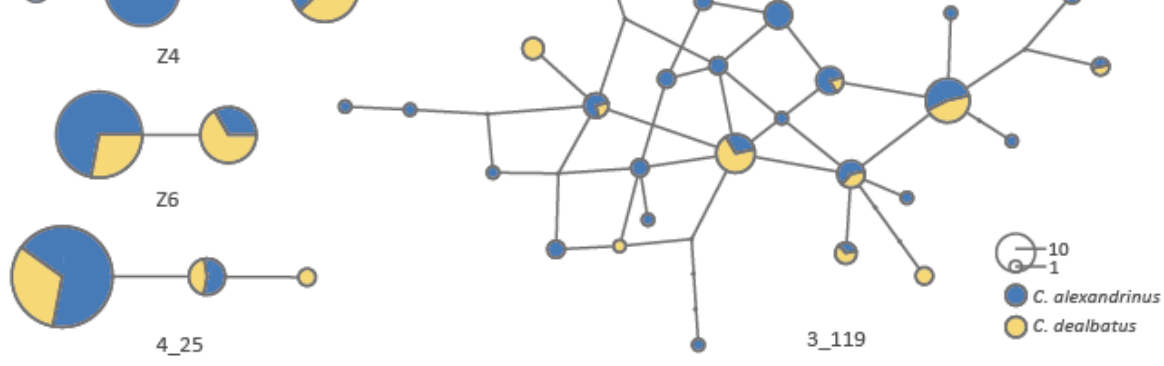

(c)

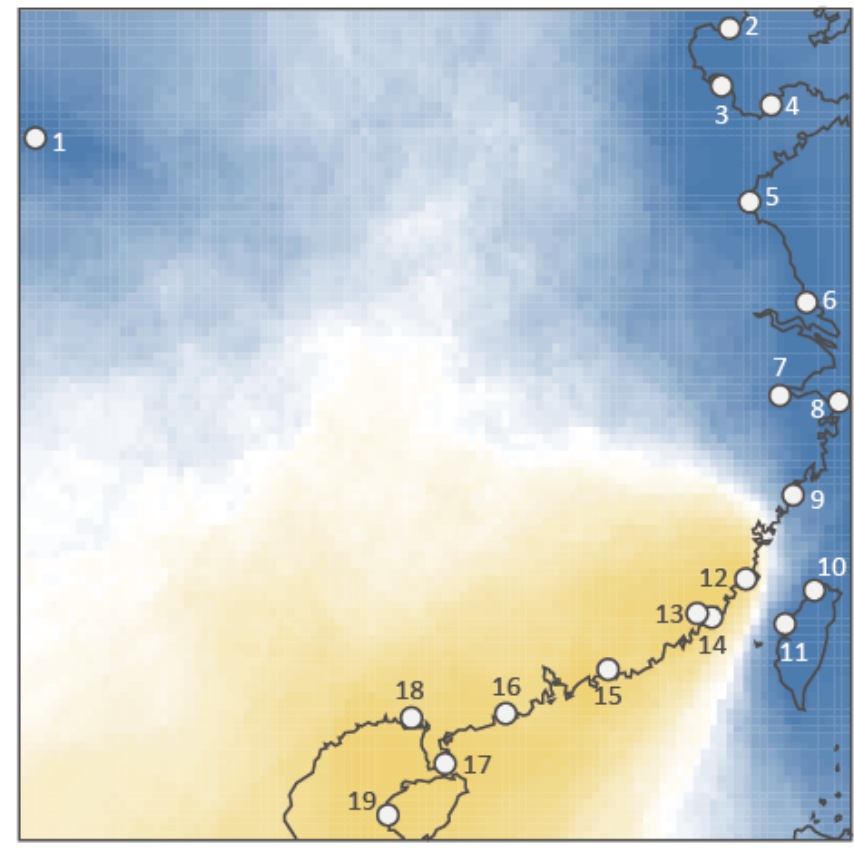

(d) 0.00 .20 .40 .60 .81 .0

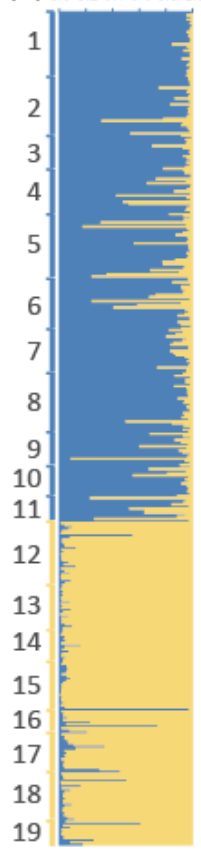


bioRxiv preprint doi: https://doi.org/10.1101/406041; this version posted August 31, 2018. The copyright holder for this preprint (which was not certified by peer review) is the author/funder, who has granted bioRxiv a license to display the preprint in perpetuity. It is made available under aCC-BY-NC-ND 4.0 International license.

\section{FIGURE 3}

1072

(a). Divergence time

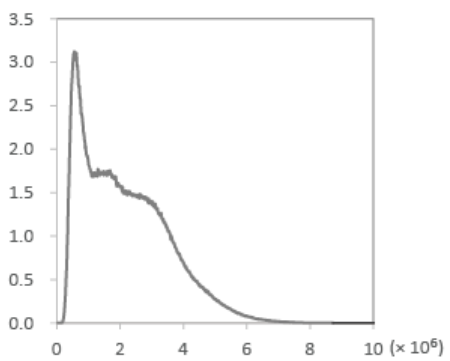

(b). Population migration rate

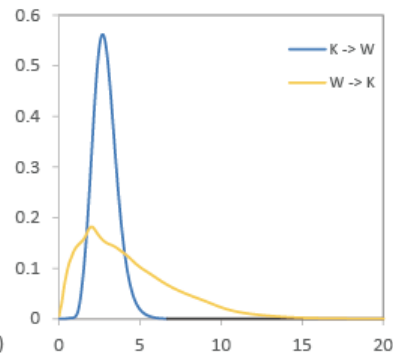

(c). Effective population size

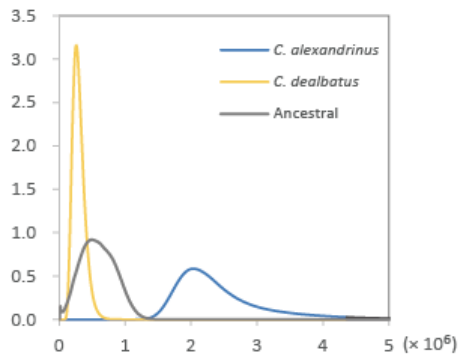

1074 
bioRxiv preprint doi: https://doi.org/10.1101/406041; this version posted August 31, 2018. The copyright holder for this preprint (which was not certified by peer review) is the author/funder, who has granted bioRxiv a license to display the preprint in perpetuity. It is made available under aCC-BY-NC-ND 4.0 International license.

\section{6}

\section{FIGURE 4}

C. alexandrinus

LIG
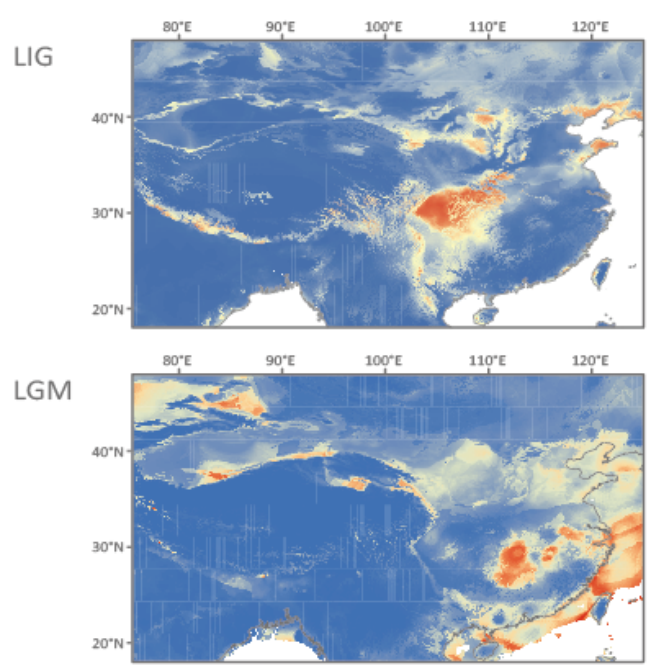

Current

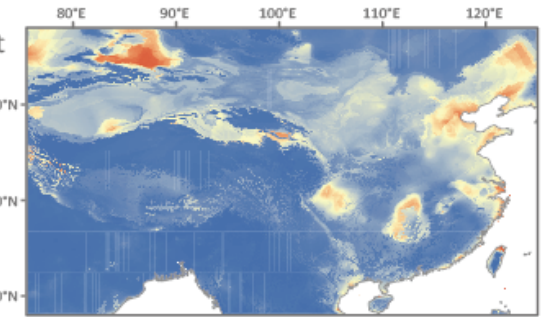

\section{C. dealbatus}
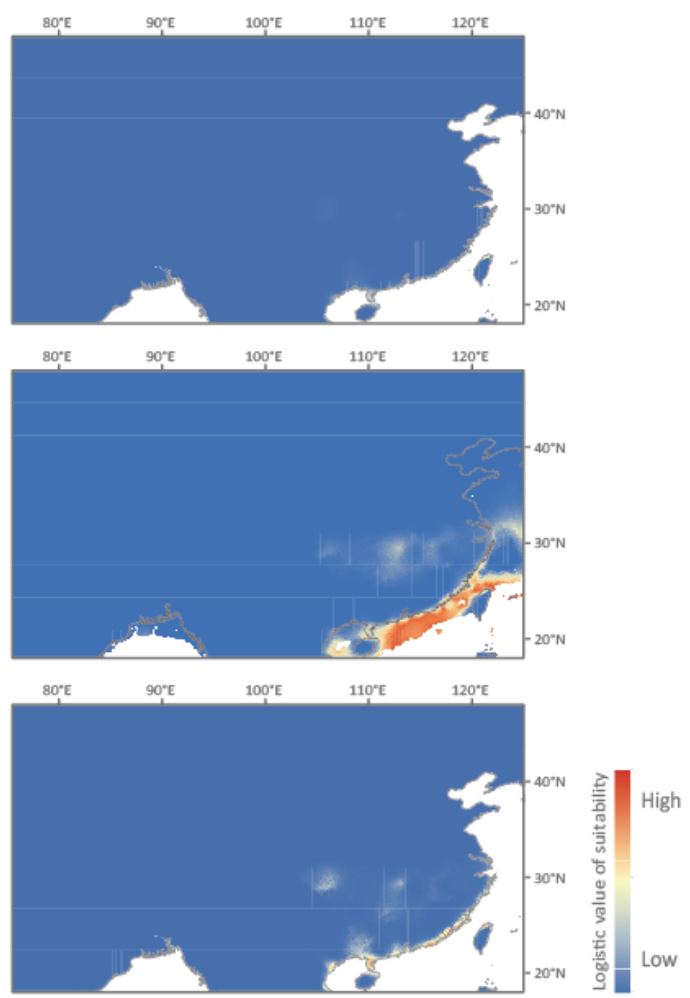

1078 
bioRxiv preprint doi: https://doi.org/10.1101/406041; this version posted Auqust 31, 2018. The copyright holder for this preprint (which was not certified by peer review) is the author/funder, who has granted bioRxiv a license to display the preprint in perpetuity. It is made available under aCC-BY-NC-ND 4.0 International license.

\section{FIGURE 5}

1080

(a)
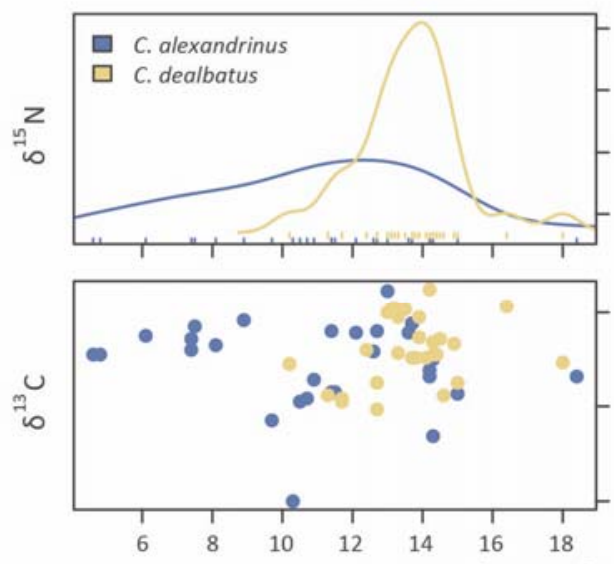

$$
\delta^{15} \mathrm{~N}
$$

Isotope Ratio (per mil)

$$
\delta^{13} \mathrm{C}
$$
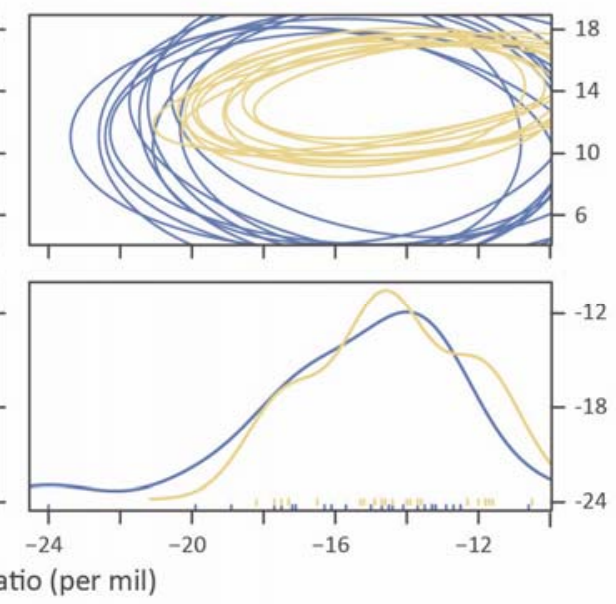

(b)

C. dealbatus in C. alexandrinus

C. alexandrinus in C. dealbatus

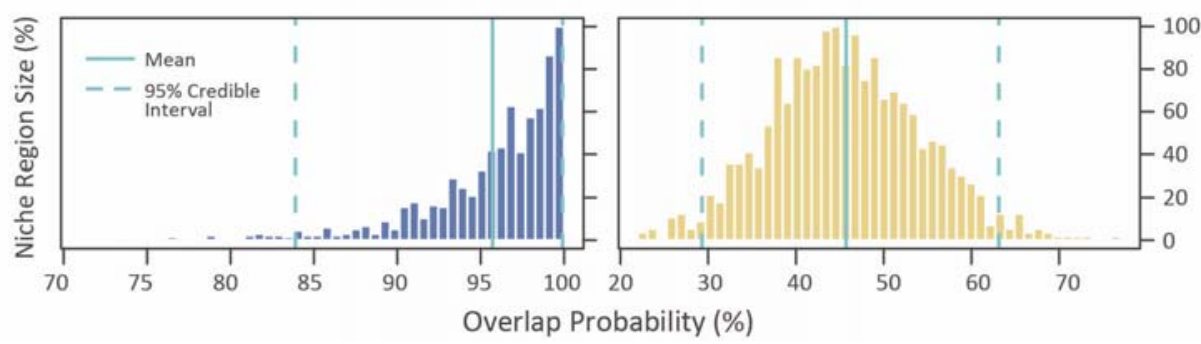

1082 
TABLE 1 Sampling localities and genetic polymorphism of $C$. alexandrinus and $C$.

1084 dealbatus. The number of individuals $(n)$ analyzed for mtDNA, autosomal microsatellites and nuclear exonic loci (nuDNA) are given. Site number corresponds to

1086 the numbers in Figure 1. Estimates of $h$, number of haplotypes; $H d$, haplotype diversity; $\pi$, nucleotide diversity; Tajima's $D$ value, $H o$, observed heterozygosity; $H e$, expected

1088 heterozygosity were calculated for each locality and species.

\begin{tabular}{|c|c|c|c|c|c|c|c|c|c|c|c|c|c|}
\hline & \multirow[b]{2}{*}{ Site } & \multirow[b]{2}{*}{ Latitude } & \multirow[b]{2}{*}{ Longitude } & \multicolumn{5}{|c|}{ mtDNA } & \multicolumn{3}{|c|}{ Microsatellites } & \multicolumn{2}{|c|}{ nuDNA } \\
\hline & & & & $n$ & $h$ & $H d$ & $\pi$ & Tajima's D & $n$ & Ho & $\mathrm{He}$ & $n$ & $\begin{array}{c}\text { Tajima's } \\
\text { D }\end{array}$ \\
\hline \multicolumn{2}{|c|}{ C. alexandrinus } & & & 224 & 86 & 0.929 & 0.00181 & $-1.863^{\star}$ & 219 & 0.723 & 0.802 & $30-40$ & 0.216 \\
\hline 1 & Qinghai Lake & 36.693 & 100.758 & 30 & 13 & 0.846 & 0.00119 & -1.785 & 30 & 0.703 & 0.756 & $13-22$ & \\
\hline 2 & Tangshan & 39.169 & 118.772 & 23 & 16 & 0.945 & 0.00171 & -1.434 & 30 & 0.797 & 0.800 & $12-20$ & \\
\hline 3 & Cangzhou & 38.471 & 117.682 & 14 & 8 & 0.868 & 0.00097 & -0.871 & 16 & 0.774 & 0.791 & & \\
\hline 4 & Weifang & 37.131 & 119.484 & 21 & 14 & 0.895 & 0.00158 & -1.687 & 22 & 0.671 & 0.787 & & \\
\hline 5 & Lianyungang & 34.742 & 119.243 & 28 & 20 & 0.963 & 0.00189 & -1.166 & 30 & 0.697 & 0.777 & & \\
\hline 6 & Nantong & 32.575 & 121.043 & 25 & 12 & 0.913 & 0.00185 & -0.016 & 26 & 0.731 & 0.796 & & \\
\hline 7 & Zhoushan & 29.991 & 122.151 & 19 & 11 & 0.924 & 0.00111 & -0.141 & 20 & 0.746 & 0.779 & & \\
\hline 8 & Ningbo & 30.205 & 120.918 & 25 & 18 & 0.963 & 0.00179 & -0.958 & 29 & 0.751 & 0.793 & & \\
\hline 9 & Wenzhou & 27.937 & 120.919 & 14 & 13 & 0.989 & 0.00161 & -1.048 & 16 & 0.740 & 0.768 & & \\
\hline 10 & Xinbei & 25.862 & 119.614 & 14 & 6 & 0.736 & 0.00108 & -0.971 & 30 & 0.672 & 0.700 & $2-8$ & \\
\hline 11 & Zhanghua & 24.559 & 118.297 & 11 & 5 & 0.709 & 0.00076 & -0.893 & 22 & 0.692 & 0.669 & $4-8$ & \\
\hline \multicolumn{2}{|c|}{ C. dealbatus } & & & 133 & 29 & 0.667 & 0.00086 & $-1.989^{\star}$ & 131 & 0.714 & 0.758 & $23-28$ & 0.326 \\
\hline 12 & Jinmen & 24.448 & 118.600 & 13 & 7 & 0.731 & 0.00110 & -1.362 & 15 & 0.733 & 0.703 & $5-8$ & \\
\hline 13 & Fuzhou & 25.190 & 121.392 & 29 & 12 & 0.874 & 0.00108 & -1.445 & 15 & 0.718 & 0.761 & & \\
\hline 14 & Xiamen & 24.162 & 120.402 & 18 & 6 & 0.699 & 0.00075 & -1.532 & 12 & 0.755 & 0.748 & & \\
\hline 15 & Shanwei & 22.798 & 115.418 & 15 & 3 & 0.590 & 0.00039 & 0.221 & 23 & 0.669 & 0.696 & & \\
\hline 16 & Yangjiang & 21.589 & 111.758 & 10 & 5 & 0.822 & 0.00158 & -0.144 & 11 & 0.713 & 0.718 & & \\
\hline 17 & Zhanjiang & 20.238 & 109.921 & 18 & 7 & 0.569 & 0.00099 & -1.696 & 20 & 0.719 & 0.721 & & \\
\hline 18 & Beihai & 21.426 & 109.196 & 18 & 4 & 0.314 & 0.00044 & $-1.849^{*}$ & 23 & 0.692 & 0.695 & $18-12$ & \\
\hline 19 & Dongfang & 19.234 & 109.804 & 12 & 2 & 0.167 & 0.00019 & -1.141 & 12 & 0.763 & 0.679 & & \\
\hline All & & & & 357 & 109 & 0.922 & 0.00216 & -1.741 & 402 & 0.719 & 0.780 & $55-80$ & 0.271 \\
\hline
\end{tabular}


TABLE 2 Hierarchical analyses of molecular variance (AMOVA) based on

1092 concatenated mtDNA data and 13 microsatellite loci for $C$. alexandrinus and $C$.

dealbatus. Samples were partitioned in three groupings: 2 groups (C. alexandrinus

1094 and C. dealbatus); 3 groups (C. alexandrinus continental populations and Taiwan island populations, C. dealbatus); 4 groups (C. alexandrinus inland (Qinghai Lake), C.

1096 alexandrinus coastal, C. alexandrinus Taiwan island, and C. dealbatus). Va, genetic variation among groups; $\mathrm{Vb}$, variation among populations within groups; $V \mathrm{c}$, variation

1098 within populations. Between-group genetic differentiation was highest when populations were partitioned into two groups (C. alexandrinus and $C$. dealbatus).

1100

\begin{tabular}{ccccc}
\hline & Grouping & $\boldsymbol{V a} / \%$ & $\boldsymbol{V b} / \%$ & $\boldsymbol{V} \boldsymbol{c} / \%$ \\
\hline \multirow{3}{*}{ mtDNA } & $\mathbf{2}$ & $\mathbf{4 9 . 7 1 2}$ & $\mathbf{8 . 4 9 1}$ & $\mathbf{4 1 . 7 9 7}$ \\
& 3 & 45.695 & 9.269 & 45.036 \\
& 4 & 41.782 & 10.296 & 47.922 \\
\hline \multirow{4}{*}{ microsatellites } & $\mathbf{2}$ & $\mathbf{2 . 4 1 6}$ & $\mathbf{1 . 7 9 8}$ & $\mathbf{9 5 . 7 8 6}$ \\
& 3 & 2.192 & 1.749 & 96.059 \\
& 4 & 1.917 & 1.776 & 96.307 \\
\hline
\end{tabular}

$1102 \quad$ All $p<0.001$ 
1104 TABLE 3 Posterior mode, mean and range of 95\% highest probability distribution (HPD) of six demographic parameters inferred with IMa2p between C. alexandrinus

1106 and $C$. dealbatus. Divergence times $(T)$ are given in million years ago (Ma). The effective population size $(\mathrm{Ne})$ of $C$. alexandrinus was about eight times that of $C$.

1108 dealbatus. Migration rate (2NM) into each species was about the same. $\mathrm{K}$ represents Kentish Plover C. alexandrinus; W represents White-faced Plover C. dealbatus; $A$ is

1110 the most recent common ancestor of two species.

\begin{tabular}{lrrrrrr}
\hline Parameter & $T / \mathrm{Ma}$ & $\mathrm{Ne}_{W} / 10^{6}$ & $N e_{K} / 10^{6}$ & $N e_{A} / 10^{6}$ & $2 N M_{K-W}$ & $2 N M_{W->K}$ \\
\hline Mode & 0.557 & 0.259 & 2.036 & 0.495 & $2.696^{*}$ & $2.005^{*}$ \\
Mean & 2.160 & 0.297 & 2.450 & 0.589 & 2.859 & 4.306 \\
2.5\% HPD & 0.413 & 0.154 & 1.590 & 0.134 & 1.581 & 0.528 \\
97.5\% HPD & 5.187 & 0.515 & 4.442 & 1.098 & 4.503 & 11.500 \\
\hline${ }^{*} p<0.001$ & & & & & &
\end{tabular}

1112 
bioRxiv preprint doi: https://doi.org/10.1101/406041; this version posted August 31, 2018. The copyright holder for this preprint (which was not certified by peer review) is the author/funder, who has granted bioRxiv a license to display the preprint in perpetuity. It is made available under aCC-BY-NC-ND 4.0 International license.

1114 